\title{
Mitochondria-related gene expression profiles in murine fibroblasts and macrophages during later stages of ectromelia virus infection in vitro
}

\author{
L. SZULC-DĄBROWSKA ${ }^{1,2}$, Z. WYŻEWSKI ${ }^{1,3}$, K. P. GREGORCZYK-ZBOROCH ${ }^{1}$, F.N. TOKA ${ }^{1,2}$, J. SZCZEPANOWSKA ${ }^{4}$, \\ J. STRUZIK ${ }^{1}, Z$. NOWAK-ŻYCZYŃSKA ${ }^{5}$, M. GIERYŃSKA ${ }^{1}$, M. NIEMIAETOWSKI $^{1 /}$
}

\begin{abstract}
${ }^{1}$ Department of Preclinical Sciences, Institute of Veterinary Medicine, Warsaw University of Life Sciences-SGGW, Ciszewskiego 8, 02-786 Warsaw, Poland; ${ }^{2}$ Integrative Mammalian Research Center, Ross University School of Veterinary Medicine, P.O. Box

334, Basseterre, St. Kitts, West Indies; ${ }^{3}$ Faculty of Biological Sciences, Cardinal Stefan Wyszynski University in Warsaw, Warsaw, Poland; ${ }^{4}$ Nencki Institute of Experimental Biology Polish Academy of Sciences, Warsaw, Poland; ${ }^{5}$ Department of Animal Genetics and Conservation, Institute of Animal Sciences, Warsaw University of Life Sciences-SGGW, Warsaw, Poland
\end{abstract}

Received July 7, 2019; accepted December 16, 2019

\begin{abstract}
Summary. - Mitochondria are multitasking organelles that play a central role in energy production, survival and primary host defense against viral infections. Therefore, viruses target mitochondria dynamics and functions to benefit their replication and morphogenetic processes. We endeavor to understand the role of mitochondria during infection of ectromelia virus (ECTV), hence our investigations on mitochondria-related genes in non-immune (L929 fibroblasts) and immune (RAW 264.7 macrophages) cells. Our results show that during later stages of infection, ECTV significantly decreases the expression of mitochondria-related genes regulating many aspects of mitochondrial physiology and functions, including mitochondrial transport, small molecule transport, membrane polarization and potential, targeting proteins to mitochondria, inner membrane translocation, and apoptosis. Such down-regulation is cell-specific, since macrophages exhibited a more profound down-regulation of mitochondria-related genes compared to infected L929 fibroblasts. Only L929 cells exhibited up-regulation of two important genes responsible for oxidative phosphorylation and subsequent ATP production: Slc25a23 and Slc25a31. Changes in the expression of mitochondria-related genes are accompanied by altered mitochondria morphology and distribution in both types of cells. In depth Ingenuity Pathway Analysis (IPA) identified the "Sirtuin Signaling Pathway" as the most significant top canonical pathway associated with ECTV infection in both analyzed cell types. Taken together, down-regulation of mitochondria-related genes observed especially in macrophages indicates dysfunctional mitochondria, possibly contributing to energy collapse and induction of intrinsic pathway of apoptosis. Meanwhile, alteration of the expression of several mitochondria-related genes in fibroblasts without apoptosis induction may represent poxviral strategy to control cellular energy metabolism for efficient replication.
\end{abstract}

Keywords: ectromelia virus; mitochondria; fibroblasts; macrophages

E-mail: lidia_szulc@sggw.edu.pl; phone: +48-22 59360 66."In memoriam.

Abbreviations: $\mathrm{ANT}=$ adenine nucleotide translocase; $\mathrm{APC2}=\mathrm{ATP}-\mathrm{Mg} / \mathrm{phosphate}$ carrier 2; ECTV = ectromelia virus; HIV-1 = human immunodeficiency virus type 1; hpi = hour post infection; IPA = ingenuity pathway analysis; VACV = vaccinia virus; MAVS = mitochondrial antiviral signaling; $\mathrm{moi}=$ multi plicity of infection; TIM = translocase of the inner membrane; $\mathrm{TOM}=$ translocase of the outer membrane

\section{Introduction}

One of the most devastating infectious disease in the human history - smallpox, caused by variola virus (VARV) - has been eradicated following a global immunization campaign conducted by the World Health Organization (WHO). Together with this spectacular success of vaccination, announced on 8 May 1980, the complete cessation of vaccination against smallpox was recom- 
mended. Currently, the majority of human population has no immunity against smallpox and other orthopoxvirus infections (Shchelkunov, 2013). Meanwhile, observations show that incidences of zoonotic orthopoxvirus diseases are increasing in humans, and companion and domestic animals (Tack and Reynolds, 2011). Broad host range orthopoxviruses, such as cowpox (CPXV), monkeypox (MPXV) and vaccinia (VACV) viruses are able to infect cats, dogs, domestic rodents, monkeys and/or other animals, and such infected animals have been implicated in human disease outbreaks (Reed et al., 2004; Abrahao et al., 2009; Tack and Reynolds, 2011). Additionally, other poxviruses belonging to the Parapoxvirus and Capripoxvirus genera are responsible for serious pox diseases of domesticated ruminants (Rohde et al., 2012; Murray et al., 2013).

Orthopoxvirus infections in domestic animals can be nearly asymptomatic or cause papular or vesicular rash, upper respiratory signs, or may even result in death (Tack and Reynolds, 2011). Cats infected with CPXV may develop focal cutaneous lesions with no systemic signs, however severe cases with fatal necrotizing pneumonia have been reported (McInerney et al., 2016). MPXV, which is endemic in rodent population in Africa, was responsible for an outbreak in 2003 in the United States that occurred among persons who had had contact with infected prairie dogs exposed to rodents imported from West Africa (Reed et al., 2004). Moreover, in different parts of Brazil regions, VACV causes infections in milking cows and dairy workers (bovine vaccinia), characterized by exanthematous lesions on the teats and hands, respectively. Milk from infected cows may contain live VACV particles, therefore, it can be a potential source of viral transmission to humans (Abrahao et al., 2009). Because the risk of zoonotic poxvirus outbreaks can increase in the future, there is a need to study orthopoxviral immunobiology in order to develop effective therapeutics for both animals and humans.

Currently, the best small animal model to study pathogenesis of smallpox and other orthopoxvirus infections as well as the virus-host cell interactions is a murine model of ectromelia virus (ECTV) infection (Buller, 2004). ECTV is an orthopoxvirus that infects laboratory mice causing mousepox - a systemic disease lethal for certain strains of mice (Parker et al., 2010). During co-evolution with the natural host, ECTV (a narrow host-range orthopoxvirus) acquired sophisticated and host-specific strategies to control sub-cellular architecture and cellular functions of different types of murine cells to effectively replicate in them (Szulc-Dabrowska et al., 2016, 2017a,b).

Mitochondria play a central role in extremely important cellular processes needed for virus survival and spread, e.g., energy production and primary antiviral immune response. Mitochondria generate energy in the form of ATP, which is synthesized during glucose me- tabolism through oxidative phosphorylation (Bertram et al., 2006). Viruses do not have biological machinery to generate and store energy in the form of ATP, therefore they utilize mitochondria-derived energy to replicate and escape from the cell (Anand and Suresh, 2013). Numerous viruses, including human immunodeficiency virus type 1 (HIV-1) (Radovanović et al., 1999), respiratory syncytial virus (RSV) (Hu et al., 2017), ECTV (Gregorczyk et al., 2014, 2018) and African swine fever virus (ASFV) (Rojo et al., 1998) induce clustering of mitochondria around virus replication centers (viral factories) to provide energy needed for replication and/or morphogenesis of progeny virions. Furthermore, viruses can alter mitochondria dynamics (fusion and fission) to modulate the intrinsic pathway of apoptosis and interfere with cellular signaling pathways (Khan et al., 2015). Because mitochondrial dynamics is regulated by mitochondrial antiviral signaling (MAVS) protein that facilitates the mitochondria-ER association required for signal transduction, viruses can promote mitochondria fragmentation to alter downstream MAVS signaling and ultimately inhibiting type I interferon (IFN) production (Castanier et al., 2009; Koshiba, 2013; Wyżewski et al., 2016). Orthopoxviruses, as masters of immune evasion strategies, often modulate different mitochondrial processes for their own benefit (Bidgood and Mercer, 2015). Therefore, a better understanding of the interaction of orthopoxviruses with vital organelles, such as mitochondria, is fundamental to elucidating modulatory strategies employed by viruses and shedding new light on the pathogenesis of orthopoxviral infections.

Our previous studies have indicated that ECTV affects mitochondria distribution, morphology and physiology in L929 fibroblasts (Gregorczyk et al., 2014, 2018) and RAW 264.7 macrophages (Gregorczyk et al., 2018) in vitro. In both types of cells, ECTV infection, at later stages, leads to the reduction of mitochondrial membrane potential and mitochondrial mass, causes the imbalance between mitochondrial fission-fusion, and increases the production of reactive oxygen species (ROS), suggesting damage to mitochondria later in infection. Interestingly, despite mitochondrial network disorganization, in L929 cells the induction of apoptosis does not occur (Gregorczyk et al., 2018). However, it is not known how ECTV influences the global mitochondrial gene expression profile in permissive cells during later stages of infection. Therefore, in the present study we assessed the mitochondria-related gene expression profile in fibroblasts (in which ECTV displays strong anti-apoptotic capabilities) and macrophages (in which apoptosis is induced) upon ECTV infection in vitro. Fibroblasts and tissue macrophages are usually present at sites of poxvirus entry, thus they serve as the best cell types to model mitochondrial response to poxvirus replication upon entry into tissues. 


\section{Materials and Methods}

Cell lines. L929 cells (CCL-1), derived from normal subcutaneous areolar and adipose tissue of $\mathrm{C} 3 \mathrm{H} / \mathrm{An}$ mouse, and RAW 264.7 cells (TIB-71), derived from macrophages of BALB/c mouse, were purchased from the American Type Culture Collection (ATCC; USA). L929 and RAW 264.7 cells were cultured in high glucose DMEM (HyClone, USA) or RPMI 1640 (Gibco; Thermo Fisher Scientific, USA) medium, respectively, supplemented with $5 \%$ or $10 \%$ fetal bovine serum (FBS; Sigma-Aldrich, USA) and $1 \%$ antibiotic-antimycotic $(100 \mathrm{U} / \mathrm{ml}$ penicillin, $100 \mathrm{\mu g} / \mathrm{ml}$ streptomycin and $0.25 \mathrm{\mu g} / \mathrm{ml}$ amphotericin B; Sigma-Aldrich) or $1 \%$ antibiotic $(100 \mathrm{U} / \mathrm{ml}$ penicillin and $100 \mu \mathrm{g} / \mathrm{ml}$ streptomycin; Sigma-Aldrich) solution. African green monkey kidney (Vero) cells (ATCC, CCL-81) were used for virus propagation and titration. Vero cells were maintained in high glucose DMEM (HyClone) enriched with 5\% FBS (HyClone) and 1\% antibioticantimycotic solution (Sigma-Aldrich). All cells were incubated at $37^{\circ} \mathrm{C}$ in a $5 \% \mathrm{CO}_{2}$ humidified atmosphere.

Virus and cell infection. The Moscow strain of ECTV (ATCC, VR-1374) was propagated on Vero cells for 5 days at $37^{\circ} \mathrm{C}$ in a $5 \% \mathrm{CO}_{2}$ humidified atmosphere. Virus stock was purified by sucrose cushion centrifugation, as previously described (Szulc-Dąbrowska et al., 2017a). The virus titer was determined by plaque formation on Vero cells. L929 fibroblasts and RAW 264.7 macrophages were incubated with ECTV at a multiplicity of infection $(\mathrm{moi})=1$ for $1 \mathrm{~h}$ at $37^{\circ} \mathrm{C}$, as previously described (Szulc-Dąbrowska et al., 2017a). Next, non-cell-attached virus was removed from culture and fresh culture medium was added. The culturing continued for $24 \mathrm{~h}$ at $37^{\circ} \mathrm{C}$ in a $5 \% \mathrm{CO}_{2} \mathrm{hu}-$ midified atmosphere. Control cells were processed identically without ECTV infection.

RNA isolation and reverse transcription (RT). RNA isolation was performed using Qiagen RNeasy mini kit (Qiagen, Inc., USA), according to the manufacturer's protocol. Briefly, $1 \times 10^{6}$ cells seeded in each well of a 6-well plate were lysed using RLT buffer supplemented with $1 \% \beta$-mercaptoethanol (Sigma-Aldrich). Additionally, to avoid genomic DNA contamination, on-column DNA digestion was performed using RNase-Free DNase set (Qiagen). The RNA concentration and purity were measured by optical density using the Take-3 system on Epoch BioTek spectrophotometer (BioTek Instruments, Inc., USA) at the absorbance of $260 \mathrm{~nm}$ and the $260 \mathrm{~nm} / 280 \mathrm{~nm}$ absorbance ratio, respectively. RNA was considered as pure when $260 \mathrm{~nm} / 280$ $\mathrm{nm}$ ratio was close to 2 . The RNA was stored at $-70^{\circ} \mathrm{C}$ until used. First strand cDNA synthesis was performed with the RT ${ }^{2}$ first strand kit (Qiagen) using oligo(dT) and random hexamers, as recommended by the manufacturer. A second genomic DNA elimination step, prior to RT, was performed by incubation of $1 \mu \mathrm{g}$ RNA in GE2 buffer for $5 \mathrm{~min}$ at $42^{\circ} \mathrm{C}$. The cDNA was stored at $-20^{\circ} \mathrm{C}$ until used.

Real-time PCR. Real-time PCR was performed using 96-well Mitochondria $\mathrm{RT}^{2}$ profiler PCR array plates (Qiagen), as previ- ously described (Szulc-Dąbrowska et al., 2017a,b). The plates contained lyophilized $\mathrm{RT}^{2} \mathrm{qPCR}$ primers for 84 mitochondrial genes, 5 reference genes (Actb, B2m, Gapdh, Gusb, and Hsp90ab1), 3 reverse transcription controls (RTC), 3 positive PCR controls (PPC) and 1 mouse genomic DNA contamination (MGDC) control (Additional file 1: Table S1). Five hundred nanograms of cDNA were mixed with $\mathrm{RT}^{2}$ SYBR Green mastermix (Qiagen) and dispensed into the $\mathrm{RT}^{2}$ profiler PCR array plates. The amplification was performed according to the manufacturer's recommendations in ABI 7500 thermocycler (Life Technologies, USA).

Data quality control. The data were subjected to quality control, including the PCR array reproducibility, RT efficiency and genomic DNA contamination. The criteria for the PCR array reproducibility were: the average $P P C C_{T}=19 \pm 3$ and no two arrays had an average $P P C C_{T}>2$ away from one another. The criterion for RT efficiency was $\Delta \mathrm{C}_{\mathrm{T}}(\mathrm{AVG} \mathrm{RTC}-\mathrm{AVG} \mathrm{PPC}) \leq 5$. The criterion for genomic DNA contamination was $C_{T}(M G D C) \geq 35$.

Data normalization and analysis. Because the expression of the in-built endogenous controls assays was not uniform between infected and non-infected cells and throughout experiment repetitions, the software at the Qiagen Data Analysis Center was queried to analyze genes with stable expression across the samples and all replicates. Thus, for L929 and RAW 264.7 Tomm20, Slc25a25, Opa1, Tomm70a and Sh3glb1 and Slc25a25, Pmaip1 and Slc25a10, respectively, were chosen for normalization. After normalization, $\Delta \Delta \mathrm{C}_{\mathrm{T}}$ values were calculated. The data were presented as fold change $\left(2^{(-\Delta \Delta C T)}\right)$ which is the normalized gene expression $\left(2^{(-\Delta c t)}\right)$ in the test sample divided by the normalized gene expression $\left(2^{(-\Delta \mathrm{Ct})}\right)$ in the control sample. Fold regulation represents fold change results in a biologically meaningful way (Szulc-Dąbrowska et al., 2017b). The Ingenuity Pathway Analysis (IPA, Qiagen) was applied to determine interaction networks between genes using a core analysis. Transcripts with differences greater than 2 -fold $(P \leq 0.05)$ found between ECTV-infected and control cells were input into IPA.

Immunofluorescence staining. L929 and RAW 264.7 cells were seeded on coverslips placed in wells of a 24-well plate, and then infected with ECTV. After $24 \mathrm{hpi}$, cells were stained for mitochondria using $300 \mathrm{nM}$ MitoRed (Sigma-Aldrich) for $20 \mathrm{~min}$. at $37^{\circ} \mathrm{C}$ in a humidified atmosphere with $5 \% \mathrm{CO}_{2}$. After fixing in $4 \%$ paraformaldehyde (PFA, Sigma-Aldrich) for $20 \mathrm{~min}$, cells were permeabilized with $0.5 \%$ Triton X-100 (Sigma-Aldrich) in PBS and blocked with $2 \%$ bovine serum albumin (BSA, SigmaAldrich) in $0.1 \%$ Triton X-100 in PBS. Then, ECTV antigens were stained for 60 min using FITC-conjugated polyclonal antibodies, obtained as previously described (Szulc-Dąbrowska et al., 2016). Nuclear and viral DNA were stained for $10 \mathrm{~min}$. with $1 \mu \mathrm{g} / \mathrm{ml}$ Hoechst 33342 (Sigma-Aldrich). At the end, slides were mounted in ProLong Gold antifade reagent (Invitrogen, Carlsbad, CA, USA). Slides were examined under fluorescence microscope (Olympus BX60) equipped with Color View III cooled CCD camera. Images were analyzed using Cell^ $\mathrm{F}$ (Olympus, Japan) and Image J software (NIH, Bethesda, USA). CellSens Dimension 


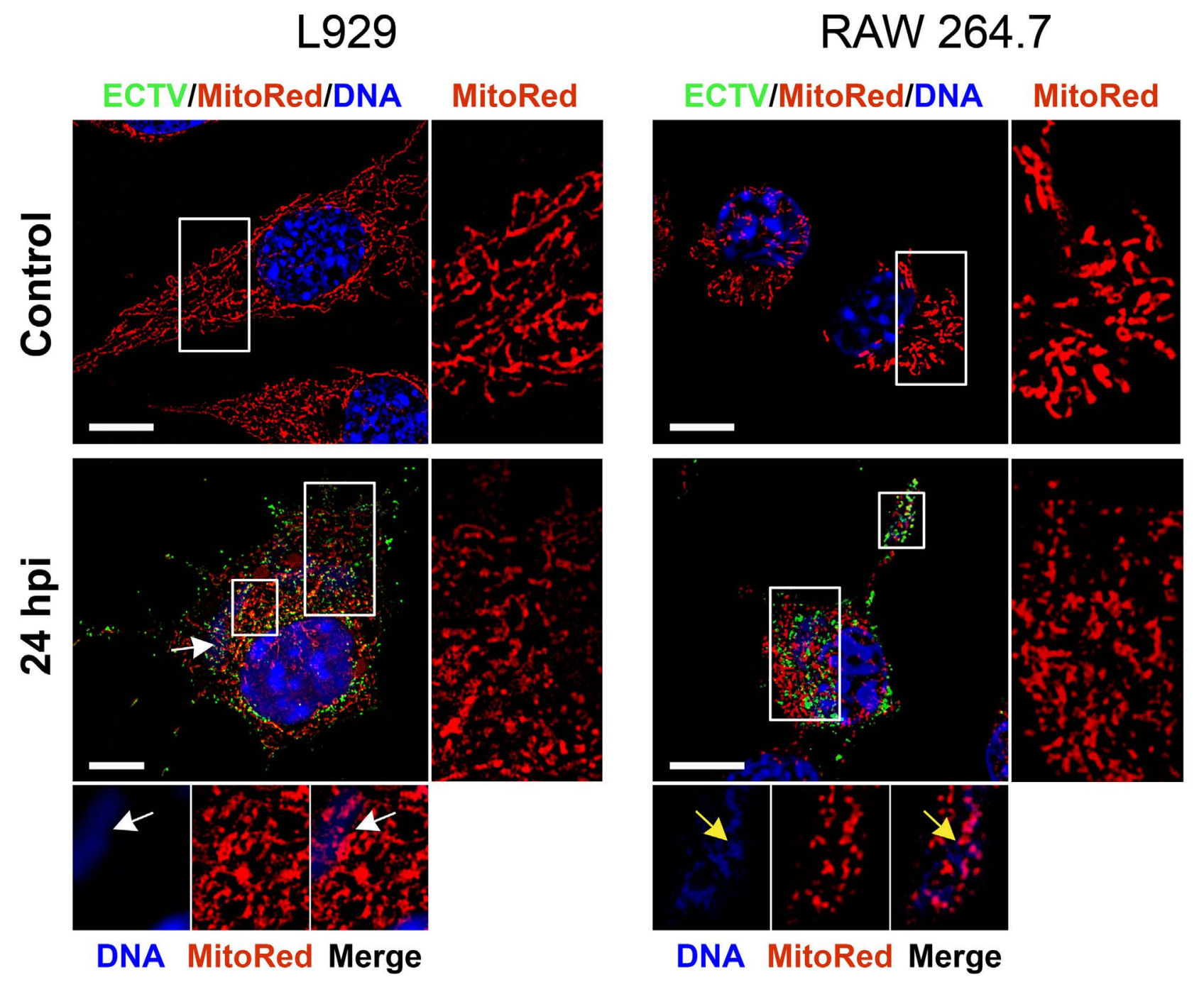

Fig. 1

Morphology of mitochondrial network in L929 fibroblasts and RAW 264.7 macrophages during ECTV infection

Cells grown on glass slides were infected with ECTV at moi $=1$ and 24 hpi were stained with 300 nM MitoRed (red fluorescence). After fixation, cells were stained for viral antigen (green fluorescence) and nuclear and viral DNA (blue fluorescence). Arrows indicate: viral factories (white) and virus particles within cellular extensions (yellow). The magnified images are of the boxed regions. Scale bars: $10 \mu \mathrm{m}$.

(Olympus) was used for 2D-deconvolution. Fluorescence microscopy images are representative of one of three independent biological replicates. The number of cells evaluated was at least 50 for each condition per individual experiment.

Statistical analysis. All experiments were biologically repeated three times independently. In qRT-PCR experiments statistical significance was calculated based on a Student t-test of the replicate $2^{(-\Delta C \mathrm{Ct})}$ values for each gene in the control and treatment groups $\left[P \leq 0.05\left(^{*}\right)\right.$ and $\left.P \leq 0.01\left(^{* *}\right)\right]$.

\section{Results}

Morphological changes of mitochondrial network in ECTV-infected cells

The morphology of mitochondrial network was assessed by fluorescence microscopy after live staining with MitoRed dye. The mitochondrial network in ECTV-infected L929 and RAW 264.7 cells at 24 hpi was fragmented compared to control uninfected cells (Fig. 1). Moreover, mitochondria displayed changed distribution and were 
(a)

L929

ECTV vs. Control (b)

RAW 264.7

ECTV vs. Control

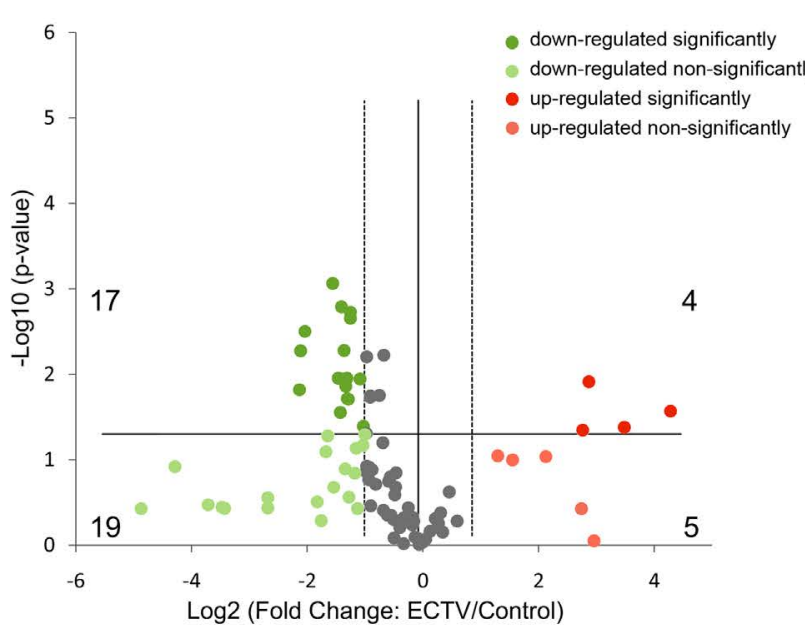

(c)

\section{L929}

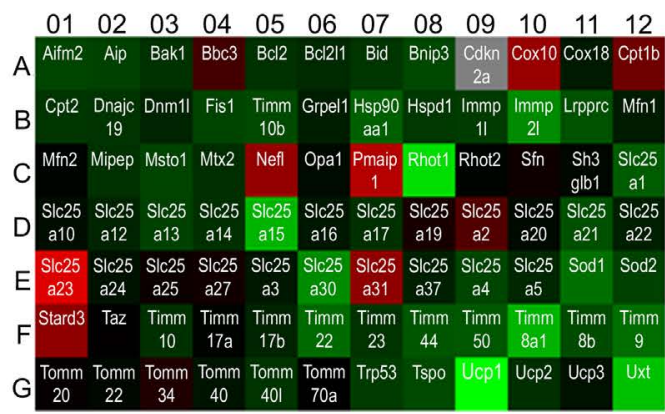

-4.871 Magnitude of log2 (Fold Change) 4.871

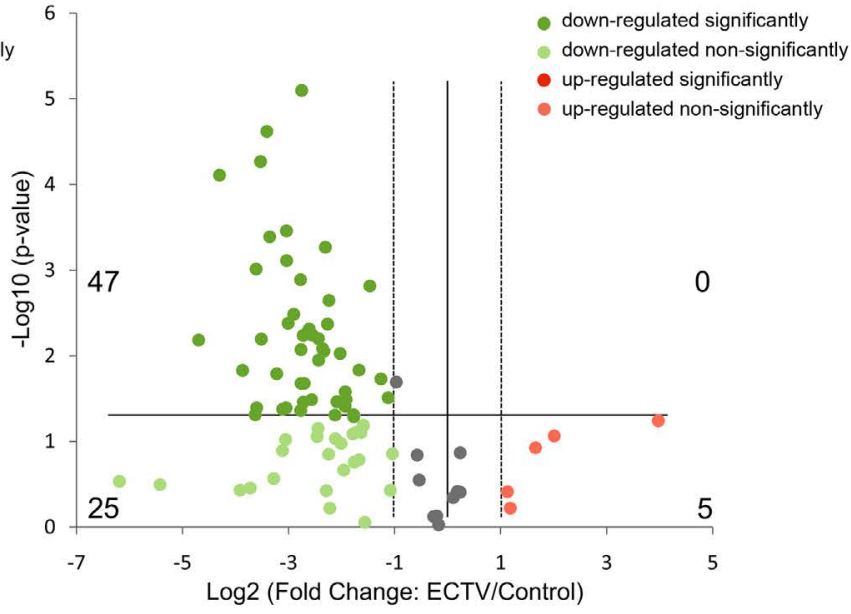

(d)

\section{RAW 264.7}

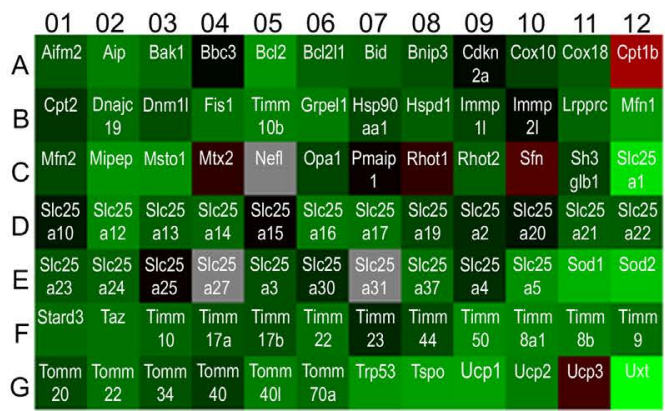

-6.188 Magnitude of log2 (Fold Change) 6.188

Fig. 2

Expression of mitochondrial genes in L929 fibroblasts and RAW 264.7 macrophages infected with ECTV

The volcano plots show differentially expressed genes in ECTV-infected vs. control L929 (a) and RAW 264.7 (b) cells. The number of genes that are significantly $(P \leq 0.05)$ down (dark green) and up (dark red)-regulated by at least 2 -fold are at the upper-left and upper-right, respectively. The number of genes that are not significantly $(P>0.05)$ down (light green)- and up (light red)-regulated by at least 2 -fold are at the lower-left and lower-right, respectively. The genes indicated in grey are less than 2-fold regulated. Heat maps of the fold-changes of gene expression between ECTV-infected and control L929 (c) and RAW 264.7 (d) cells overlaid onto the PCR array plate layout. Data were obtained from three independent biological replicates.

located near viral factories and within long cellular extensions formed in ECTV-infected cells.

Down-regulation of mitochondria-related genes is more profound in ECTV-infected macrophages than fibroblasts

We used $\mathrm{RT}^{2}$ Profiler PCR assays to analyze mitochondrial gene regulation in immune and non-immune cells upon ECTV infection. The analyzed genes were divided into ten categories as follows:(1) mitochondrial transport,
(2) small molecule transport, (3) membrane polarization and potential, (4) targeting proteins to mitochondria, (5) mitochondrion protein import, (6) outer membrane translocation, (7) inner membrane translocation, (8) mitochondrial fission and fusion, (9) mitochondrial localization, and (10) apoptosis. We used a volcano plot to visualize the differentially expressed genes, based on the 2-fold change threshold and statistical significance at $P \leq 0.05$. In the volcano plot, the $P$ value was plotted against the relative abundance ratio of ECTV-infected versus control L929 (Fig. 2a) and RAW 264.7 (Fig. 2b) cells 


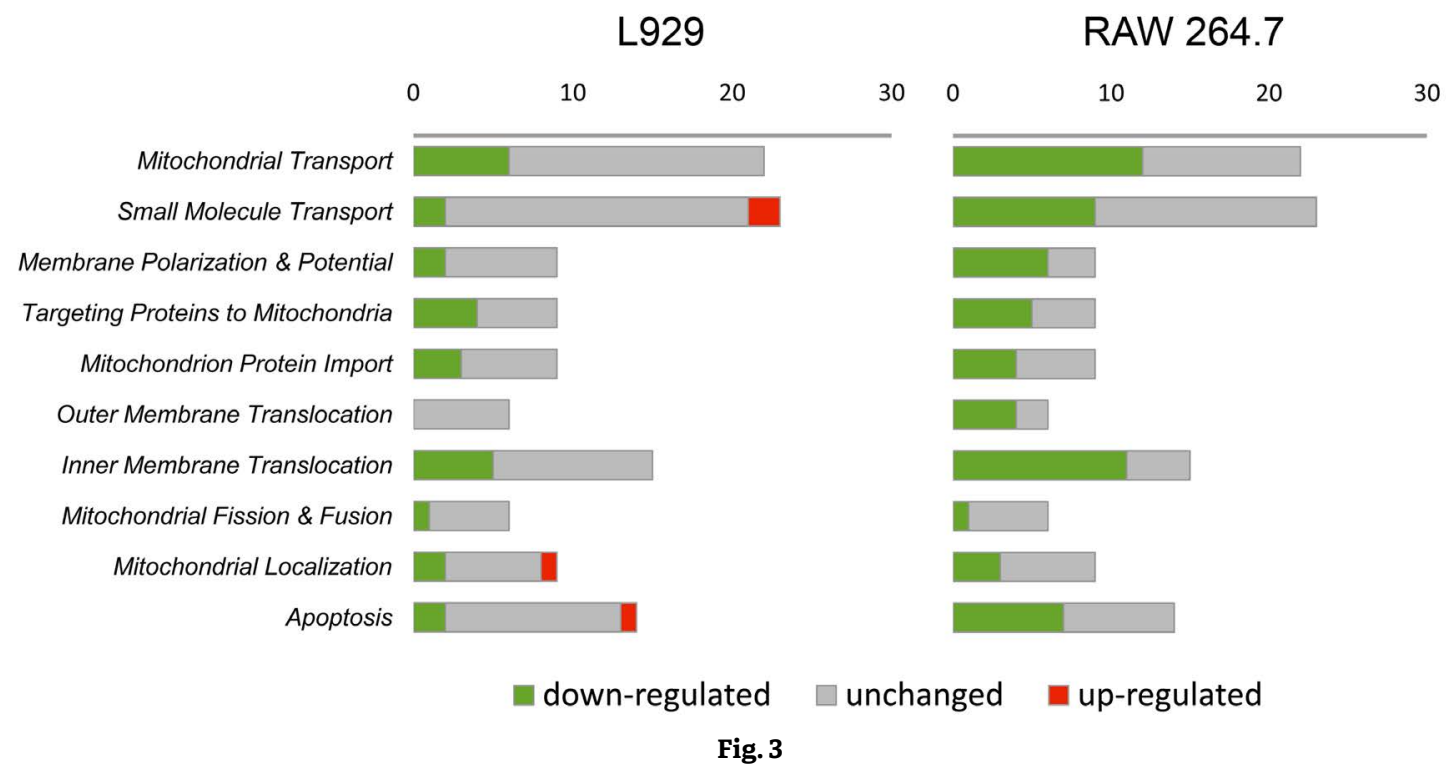

Mitochondria-related genes in L929 and RAW 264.7 cells

Number of significantly $(P \leq 0.05)$ down-regulated (green), unchanged (grey) and significantly $(P \leq 0.05)$ up-regulated (red) genes within particular mitochondrial gene categories observed in ECTV-infected L929 fibroblasts and RAW 264.7 macrophages. Data were obtained from three independent biological replicates.

on a logarithmic scale. Of the 89 genes (84 mitochondrial and 5 control genes) ECTV infection resulted in significant $(P \leq 0.05)$ down-regulation of 17 and 47 genes in $L 929$ fibroblasts and RAW 264.7 macrophages, respectively, at 24 hpi. Exceptionally, 4 genes were significantly $(P \leq 0.05)$ up-regulated in L929 cells, whereas RAW 264.7 cells did not significantly up-regulate any of the analyzed genes upon virus infection. As illustrated by the heatmaps (Fig. 2c-d), ECTV-infected L929 fibroblasts exhibited a less profound mitochondrial gene repression than infected RAW 264.7 macrophages. In L929 cells ECTV caused down-regulation of a few genes in each category with the exception of the outer membrane translocation category (Fig. 3). Within the small molecule transport, mitochondrial localization and apoptosis categories, ECTV infection up-regulated 2, 1 and 1 genes, respectively. Meanwhile, in RAW 264.7 macrophages ECTV infection suppressed the majority of mitochondrial genes in 8 out of the 10 categories (Fig. 3). Taken together the results indicate that macrophages exhibit a more profound repression of mitochondrial genes than fibroblasts during the infection with ECTV in vitro.

Expression of genes involved in mitochondrial transport and small molecule transport

Among the 22 genes analyzed in the mitochondrial transport category, 6 and 12 genes were significantly $(P \leq 0.05)$ down-regulated in ECTV-infected L929 and RAW
264.7 cells, respectively (Fig. 4a). In both cell types, the expression of Cpt2, Hspd1 and Tspo was repressed under infection, whereas Aip, Bnip3 and Timm10b were significantly $(P \leq 0.05)$ down-regulated only in fibroblasts, and Bak1, Bcl2, Bcl2l1, Dnajc19, Grpel1, Mipep, Stard3, Trp53 and Ucp2 were significantly $(P \leq 0.05)$ repressed only in macrophages.

Of the 23 genes in the small molecule transport category, only 2 genes (Slc25a4 and Slc25a13) were downand 2 genes (Slc25a23 and Slc25a31) were up-regulated in infected L929 cells (Fig. 4b). RAW 264.7 macrophages upon infection down-regulated 9 of the Solute Carrier Family genes: Slc25a3, Slc25a4, Slc25a5, Scl25a13, Scl25a16, Scl25a17, Scl25a23, Scl25a24 and Scl25a37.

Expression of genes responsible for membrane polarization and potential, and involved in targeting proteins to mitochondria

Within the membrane polarization and potential category, 2 (Bnip3 and Sod1) and 6 (Bak1 Bcl2, Bcl2l1, Sod1, Trp53 and Ucp2) genes were significantly $(P \leq 0.05)$ downregulated in ECTV-infected L929 and RAW 264.7 cells, respectively (Fig. 5a). Further, infected fibroblasts and macrophages revealed significant $(P \leq 0.05)$ repression of 4 and 5 genes, respectively, among the 9 analyzed genes involved in targeting proteins to mitochondria (Fig. 5b). In L929 fibroblasts those genes were Aip, Timm10b, Hspd1 
(a)

\section{Mitochondrial Transport}

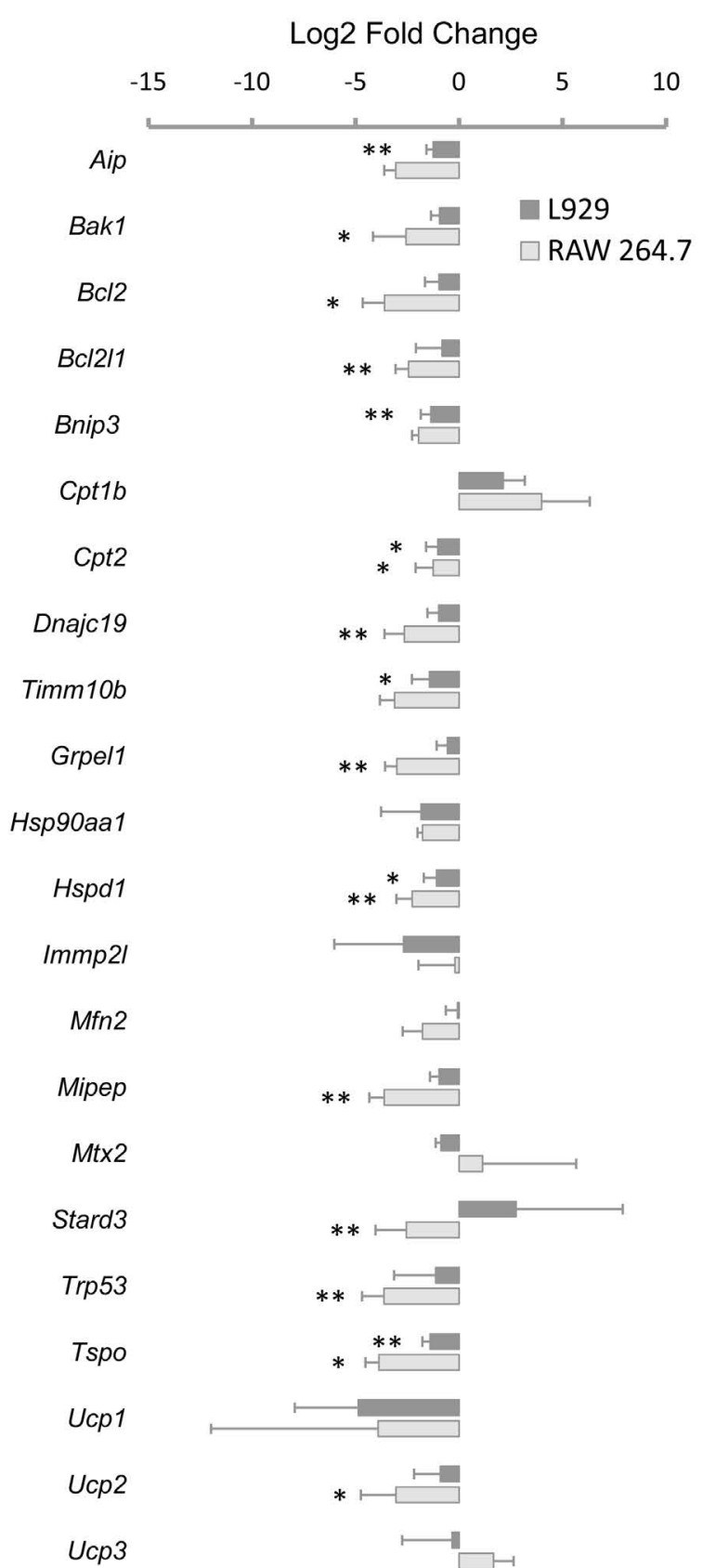

(b)

\section{Small Molecule Transport}

Log2 Fold Change

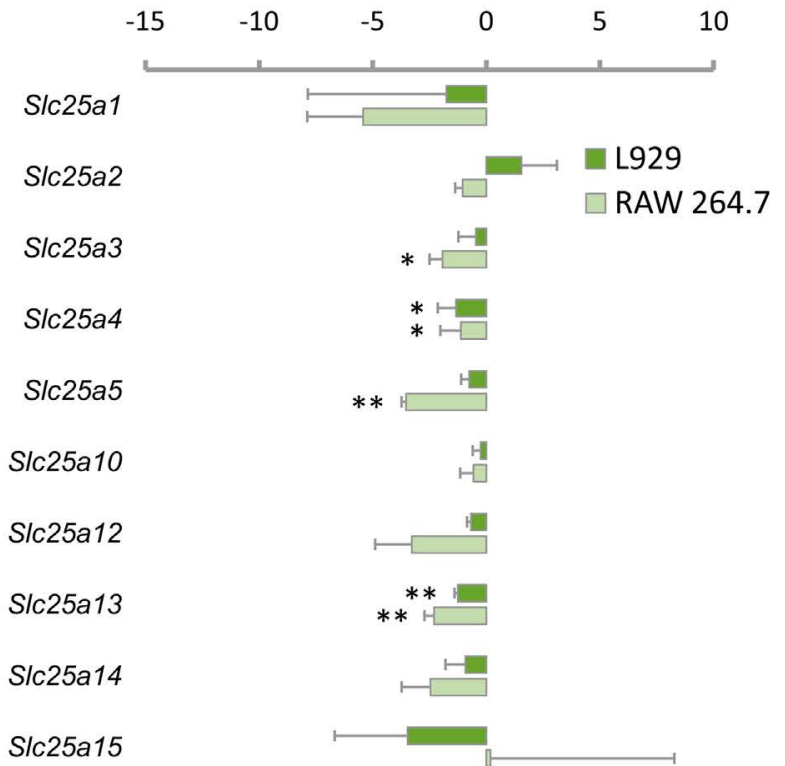

Slc25a16

Sic25a17

S/c25a19

S/c25a20

Slc25a21

S/c25a22

S/c25a23

S/c25a24

Slc25a25

Slc25a27

S/c25a30

S/c25a31

Slc25a37
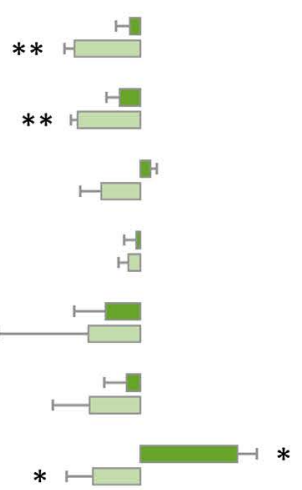

$* * \mapsto$

$\stackrel{H}{H}$

H
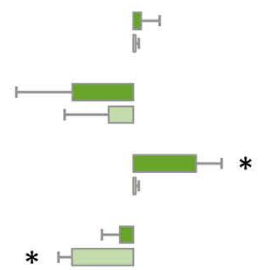

Fig. 4

Influence of ECTV infection on the expression of genes involved in regulation of mitochondrial transport in L929 fibroblasts and RAW 264.7 macrophages

Mitochondrial transport (a), small molecule transport (b). Quantitative data are expressed as mean \pm standard deviation (SD) from three independent biological replicates (Student's $t$-test; ${ }^{*} P<0.05,{ }^{\text {"** }} P<0.01$ ). 
(a)

\section{Membrane Polarization \& Potential}

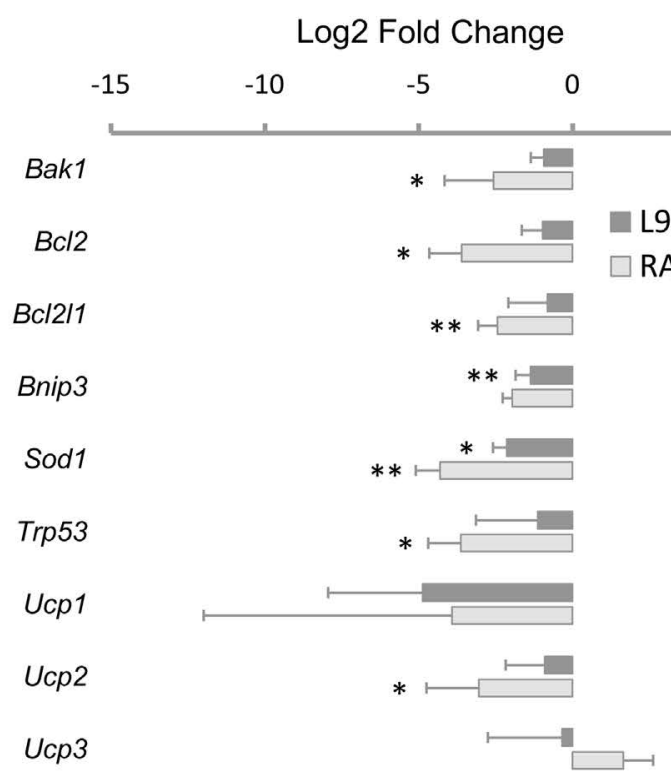

(b)

\section{Targeting Proteins to Mitochondria}

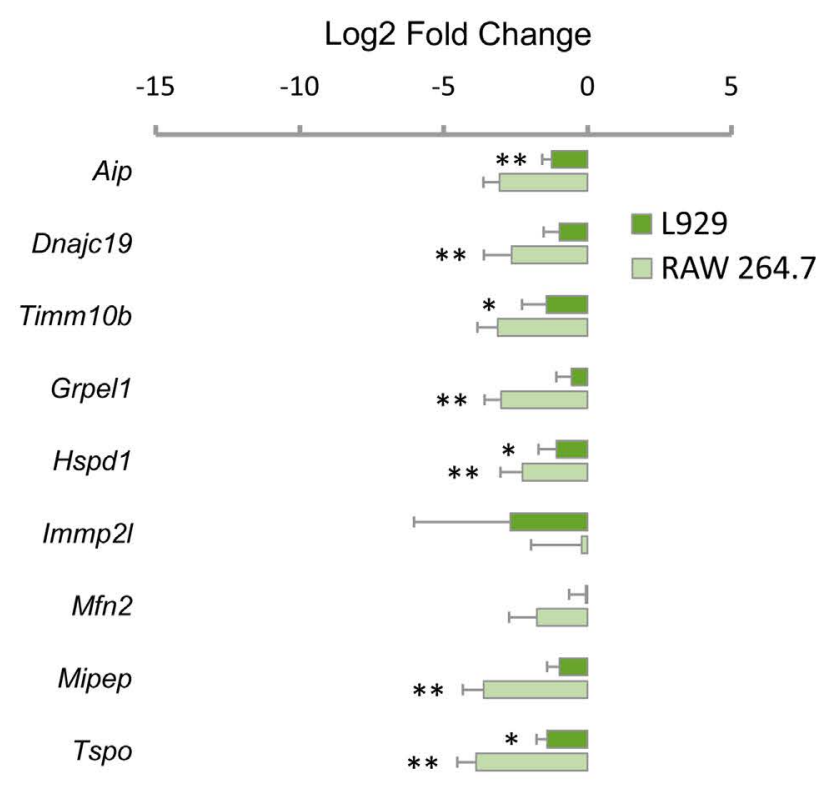

Fig. 5

Impact of ECTV infection on the expression of genes engaged in mitochondria physiology in L929 fibroblasts and RAW 264.7 macrophages

Membrane polarization and potential (a), targeting proteins to mitochondria (b). Quantitative data are expressed as mean \pm standard deviation (SD) from three independent biological replicates (Student's $t$-test; ${ }^{*} P<0.05,{ }^{, "} P<0.01$ ).

and Tspo, whereas in RAW 264.7 macrophages the affected genes were Dnajc19, Grpel1, Hspd1, Mipep and Tspo.

Expression of genes involved in mitochondrion protein import, and outer and inner membrane translocation

Within the mitochondrion protein import category, 3 and 4 genes were significantly $(P \leq 0.05)$ down-regulated in fibroblasts and macrophages, respectively, upon ECTV infection (Fig. 6a). Hspd1 was repressed in both types of cells, whereas Aip and Timm10b only in L929 fibroblasts, and Dnajc19, Grpel1 and Mipep only in RAW 264.7 macrophages. In infected L929 cells, the expression of all genes within the outer membrane translocation category remained unchanged (Fig. 6b), but in RAW 264.7 macrophages significant repression of 4 from 6 genes within this category (Tomm22, Tomm40, Tomm40l and Tomm70a) was observed.

One of the most repressed category of mitochondrial genes in both types of cells after ECTV infection was the inner membrane translocation category (Fig. 6c). Among the 15 genes, 5 and 11 genes were significantly $(P \leq 0.05)$ down-regulated in ECTV-infected L929 and RAW 264.7 cells, respectively. Timm8b, Timm9, Timm10 and Timm22 were repressed in both types of cells, whereas the expression of the remaining genes was differentially regulated. Timm $10 \mathrm{~b}$ was significantly $(P \leq 0.05)$ down-regulated only in fibroblasts, whereas the expression of Immp1l, Taz, Timm8a1, Timm17a, Timm17b, Timm44 and Timm50 was significantly $(P \leq 0.05)$ decreased only in macrophages.

Expression of genes engaged in mitochondrial fusion and fission, mitochondrial localization and apoptosis

Within the mitochondrial fission and fusion category, only Fis1 was significantly $(P \leq 0.05)$ down-regulated in ECTV-infected fibroblasts and macrophages (Fig. 7a). Expression of the remaining 5 genes was not significantly changed in both types of cells upon virus infection. Among the 9 genes in the mitochondrial localization category, 2 genes (Lrpprc and Msto1) were down- and 1 gene (Nelf) was significantly up-regulated in L929 cells infected 
(a)

\section{Mitochondrion Protein Import}

Log2 Fold Change

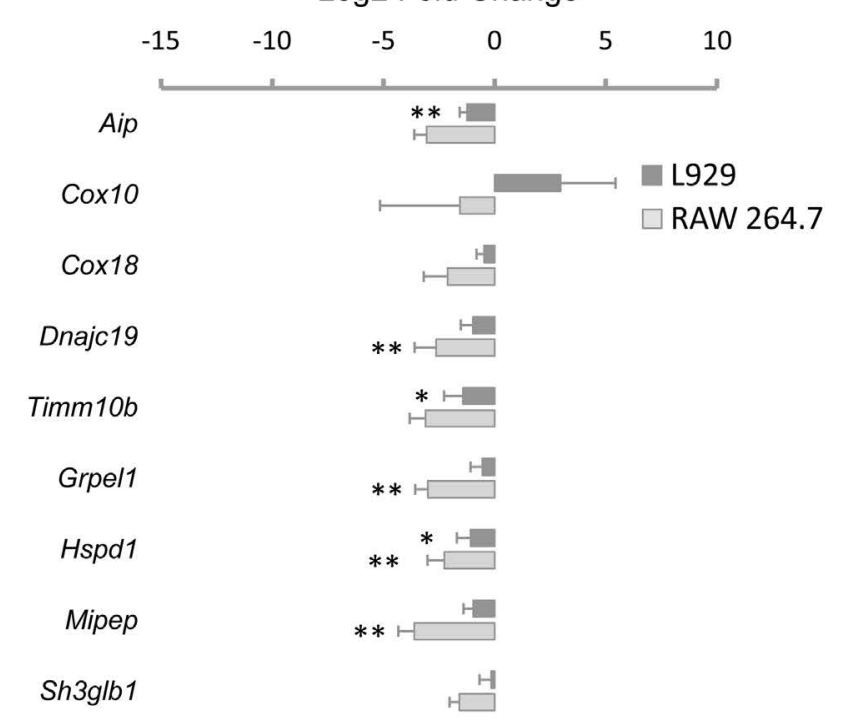

(c)

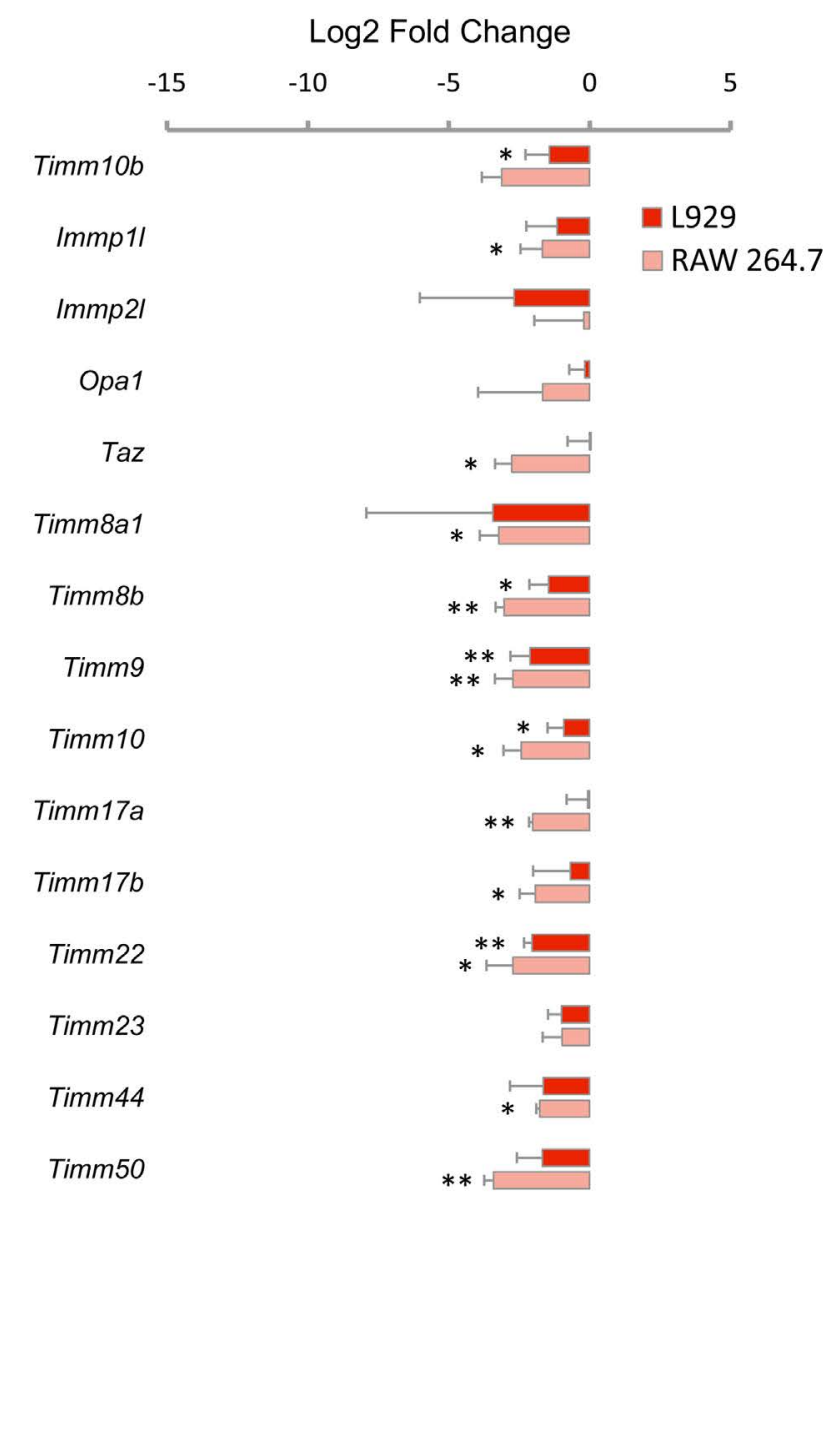

Fig. 6

Effect of ECTV infection on the expression of genes regulating protein import pathways into mitochondria in L929 fibroblasts and

\section{RAW 264.7 macrophages}

Mitochondrion protein import (a), outer membrane translocation (b), inner membrane translocation (c). Quantitative data are expressed as mean \pm standard deviation (SD) from three independent biological replicates (Student's $t$-test; ${ }^{*} P<0.05,{ }^{* *} P<0.01$ ).

with ECTV (Fig. 7b), whereas ECTV-infected macrophages exhibited significant $(P \leq 0.05)$ down-regulation of Dnm1l, Msto1 and Rhot2 (Fig. 7b).

The last analyzed category contained 14 genes involved in regulation of apoptosis (Fig. 7c). In infected L929 cells, the expression of 3 pro-apoptotic genes was differentially regulated: Aifm2 and Bnip3 were signifi- cantly $(P \leq 0.05)$ down-regulated, whereas $P$ maip1 was significantly $(P \leq 0.05)$ up-regulated. Meanwhile, in infected RAW 264.7 cells the expression of 7 genes was significantly $(P \leq 0.05)$ repressed, of which there were 3 pro-apoptotic genes (Bak1, Bid, Dnm1l), 3 anti-apoptotic genes (Bcl2, Bcl2l1, Sod2) and 1 pro-/anti-apoptotic gene (Trp53) (Fig. 7c). 
(a)

\section{Mitochondrial Fission \& Fusion}

Log2 Fold Change

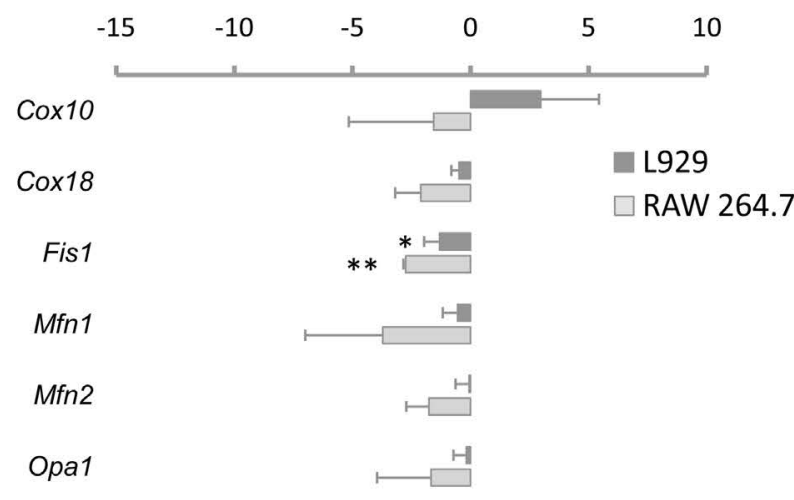

(c)

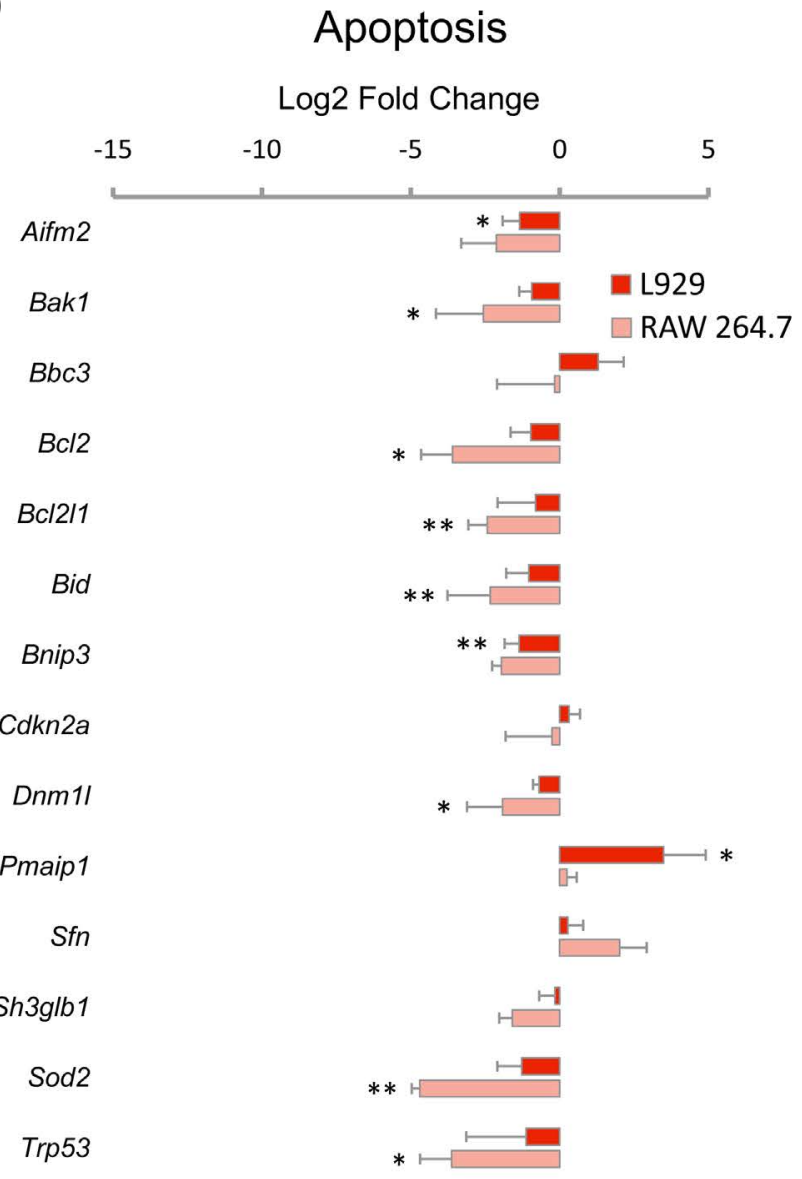

(b)

\section{Mitochondrial Localization}

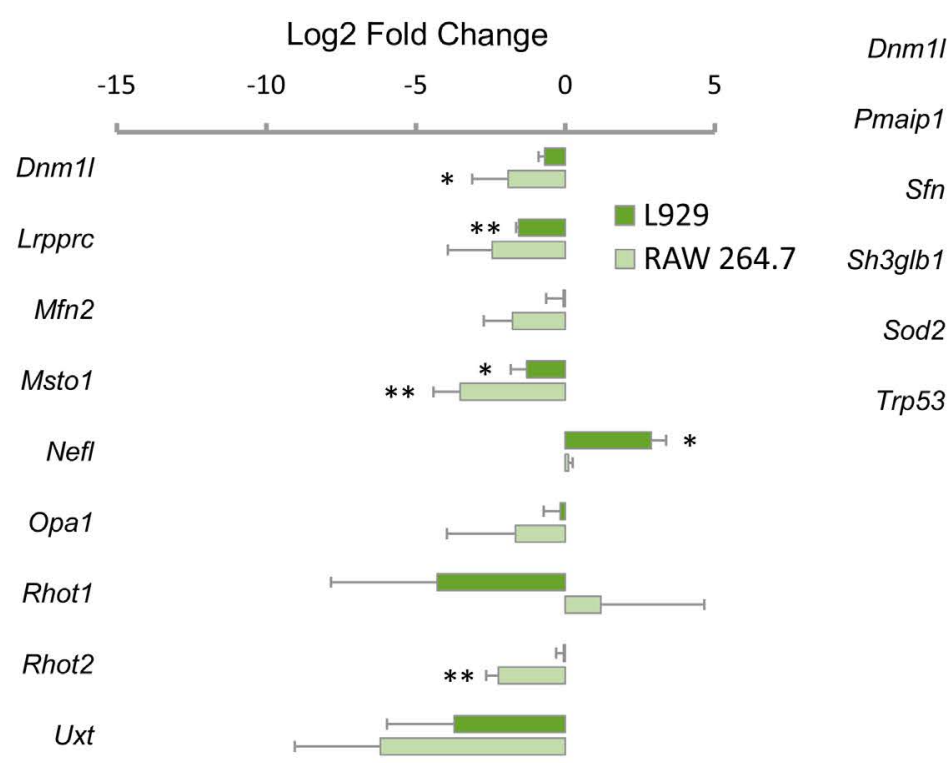

Fig. 7

Expression of genes involved in mitochondrial dynamics and apoptosis in L929 fibroblasts and RAW 264.7 macrophages infected with ECTV

Mitochondrial fission and fusion (a), mitochondrial localization (b), apoptosis (c). Quantitative data are expressed as mean \pm standard deviation (SD) from three independent biological replicates (Student's t-test; ${ }^{*} P<0.05,{ }^{, *} P<0.01$ ).

IPA analysis of mitochondrial gene-gene interaction networks in ECTV-infected fibroblasts and macrophages

The interactions between mitochondrial genes in ECTV-infected cells were investigated using the core analysis tool of IPA software. Based on the Ingenuity Knowledge Base, IPA identified "Sirtuin Signaling Path- way" and "Induction of Apoptosis by HIV1" as the most significant top two canonical pathways associated with ECTV-infection in analyzed cells (Table 1). Additionally, the canonical pathways defined as "Amyotrophic Lateral Sclerosis Signaling“, "Superoxide Radicals Degradation” and "Mitochondrial L-carnitine Shuttle Pathway" were also listed as significant pathways in L929 fibroblasts. In RAW 264.7 macrophages, analyzed genes showed sig- 
(a)
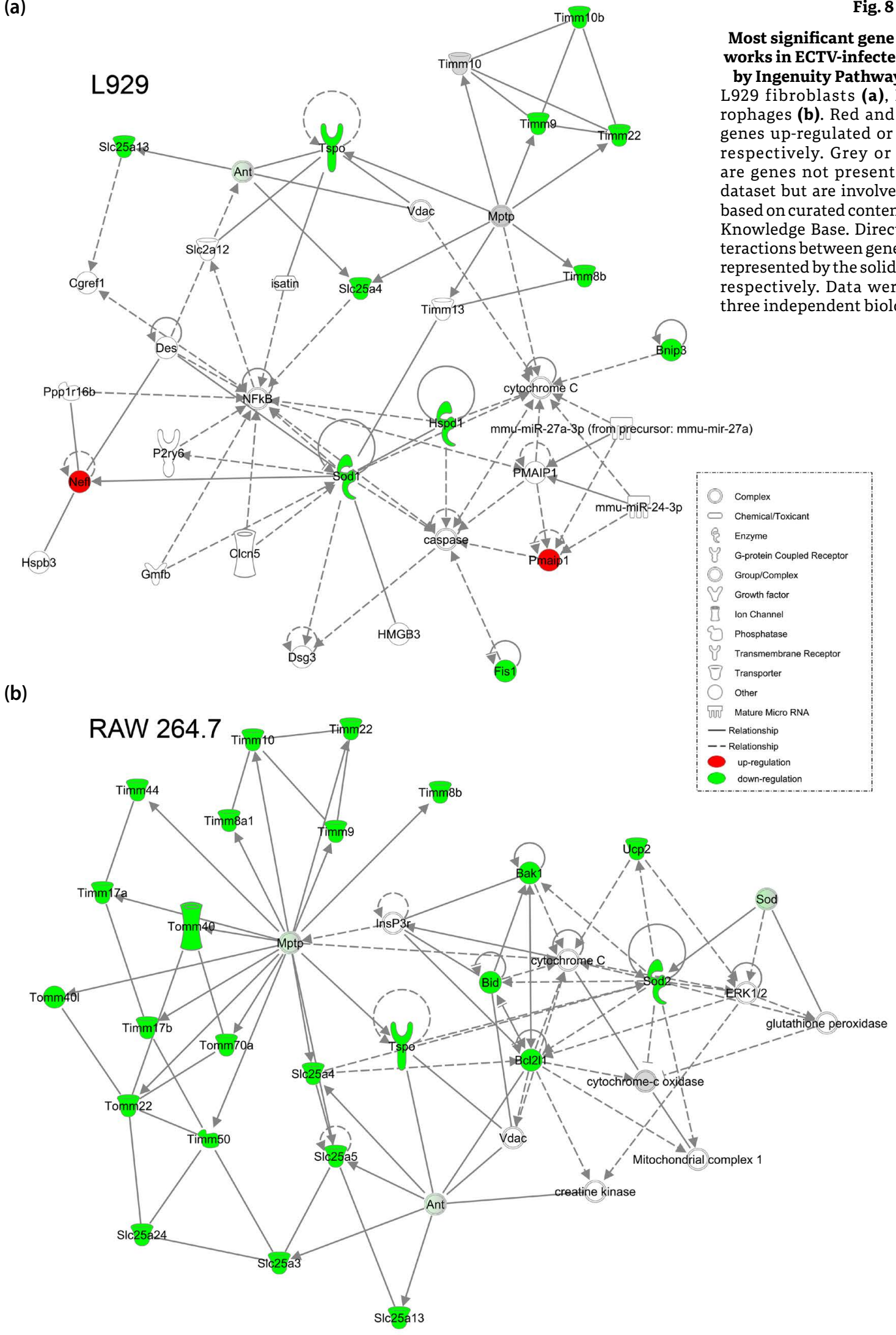

Fig. 8

Most significant gene interaction networks in ECTV-infected cells identified by Ingenuity Pathway Analysis (IPA) L929 fibroblasts (a), RAW 264.7 macrophages (b). Red and green nodes are genes up-regulated or down-regulated, respectively. Grey or colorless nodes are genes not present in the analyzed dataset but are involved in the network based on curated content of the Ingenuity Knowledge Base. Direct and indirect interactions between genes in networks are represented by the solid and dashed lines, respectively. Data were obtained from three independent biological replicates. 
Table 1. Top five canonical pathways identified by Ingenuity Pathway Analysis (IPA) of differentially expressed genes between ECTV-infected and control L929 (a) and RAW 264.7 (b) cells

\begin{tabular}{|c|c|c|c|c|}
\hline & Ingenuity canonical pathway & P value & Ratio & Molecules \\
\hline \multirow[t]{5}{*}{ a } & Sirtuin Signaling Pathway & $1.27 E-07$ & $2.10 E-02$ & Slc25a4, Sod1, Timm22, Timm8b, Timm9, Tspo \\
\hline & Induction of Apoptosis by HIV1 & $1.27 E-03$ & $3.30 E-02$ & Slc25a13, Slc25a4 \\
\hline & Amyotrophic Lateral Sclerosis Signaling & $4.14 E-03$ & $1.80 E-02$ & Nefl, Sod1 \\
\hline & Superoxide Radicals Degradation & $6.94 E-03$ & $1.25 E-01$ & Sod1 \\
\hline & Mitochondrial L-carnitine Shuttle Pathway & $1.47 E-02$ & $5.90 E-02$ & Cpt \\
\hline \multirow[t]{5}{*}{ b } & Sirtuin Signaling Pathway & $1.26 E-26$ & $6.80 E-02$ & $\begin{array}{l}\text { Slc25a4, Slc25a5, Sod1, Sod2, Timm10, Timm17a, } \\
\text { Timm17b, Timm22, Timm44, Timm50, Timm8a, } \\
\text { Timm8b, Timm9, Tomm22, Tomm40, Tomm401, } \\
\text { Tomm70, Tp53, Tspo, Ucp2 }\end{array}$ \\
\hline & Induction of Apoptosis by HIV1 & $2.93 E-15$ & $1.48 E-01$ & $\begin{array}{l}\text { Bak1, Bcl2, Bcl211, Bid, Slc25a13, Scl25a3, Slc25a4, } \\
\text { Slc25a5, Tp53 }\end{array}$ \\
\hline & Apoptosis Signaling & $1.25 E-06$ & $5.20 E-02$ & Bak1, Bcl2, Bcl2l1, Bid, Tp53 \\
\hline & Amyotrophic Lateral Sclerosis Signaling & $2.56 E-06$ & $4.50 E-02$ & Bcl2, Bcl211, Bid, Sod1, Tp53 \\
\hline & Mitochondrial Dysfunction & $2.10 E-05$ & $2.90 E-02$ & Bcl2, Fis1, Rhot2, Sod2, Ucp2 \\
\hline
\end{tabular}

nificant relationship with "Apoptosis Signaling", "Amyotrophic Lateral Sclerosis Signaling" and "Mitochondrial Dysfunction" canonical pathways (Table 1).

To determine specific and detailed relationship between up- and down-regulated genes, IPA was applied to perform network enrichment analysis in infected cells. In fibroblasts, two molecular networks were delineated: 1) "Protein Trafficking, Respiratory System Development and Function, Auditory and Vestibular System Development and Function", and 2) "Metabolic Disease, Neurological Disease, Skeletal and Muscular Disorders". The first top network in L929 cells (Fig. 8a) contained 13 genes where 2 were up-regulated and remaining 11 were down-regulated. In infected macrophages, IPA identified five molecular networks: 1) "Protein Trafficking, Cell Morphology, Cellular Function and Maintenance", 2) "Cell Death and Survival, Organismal Functions, Cardiovascular System Development and Function”,3) “Cell Morphology, Cellular Compromise, Cellular Assembly and Organization", 4) "Gastrointestinal Disease, Hepatic System Disease, Liver Steatosis", and 5) "Cellular Development, Cellular Growth and Proliferation, Skeletal and Muscular System Development and Function". The first top network in infected macrophages was represented by 24 genes, of which all were down-regulated (Fig. 8b). Taken together, our data indicate that ECTV infection leads to disruption of basic metabolic processes responsible for cellular survival, especially in macrophages.

\section{Discussion}

We evaluated the influence of ECTV infection on mitochondrial gene expression profile in non-immune (fibroblasts) and immune (macrophages) cells, because in such cells ECTV contributes to changes in mitochondrial network distribution and organization, particularly during the later stages of infection. At 18-24 hpi, the cytoplasm of infected cells is filled with "bloated" viral factories and numerous progeny virions, which are ultimately released to the extracellular environment (Szulc-Dąbrowska et al., 2016). Mitochondria tend to accumulate in the proximity of "bloated" replication centers, possibly to supply the energy needed for morphogenetic processes. Moreover, between 18-24 hpi, the mitochondrial network undergoes dramatic reorganization, accompanied by tubule fragmentation and relaxation (Gregorczyk et al., 2014, 2018), and altered mitochondria physiology (Gregorczyk et al., 2018).

In order to gain insight into virus-altered mitochondria physiology we studied the mRNA expression pattern of genes responsible for regulation of mitochondrial function during ECTV infection of fibroblasts and macrophages. The results showed that ECTV induces dramatic down-regulation of mitochondria-related gene expression, especially in RAW 264.7 cells. Several microarray and transcriptomic studies have reported that during poxvirus infection there is an absolute or relative decrease in cellular mRNAs. Further, this appears to be a global mechanism engaged by poxviruses, which facilitates replication due to silencing of cellular antiviral response and reducing competition for the translation machinery (Brum et al., 2003; Guerra et al., 2003; Yang et al., 2010). Interestingly, some of the specific host mRNAs, especially those encoding structural components of the cell, can be up-regulated during infection, allowing the poxviruses to maintain the integrity of particular cell structures to successfully complete their replication cycle (Guerra et al., 2003; Yang et al., 2010). 
In ECTV-infected cells, the most altered genes were involved in mitochondrial transport, small molecule transport, membrane polarization and potential, targeting proteins to mitochondria, inner membrane translocation and apoptosis. Our results provide a strong indication that ECTV impairs mitochondrial dynamics and function during later stages of infection, particularly in macrophages, which can be persistently infected, as shown in the spleen of BALB/c mice following acute mousepox (Spohr de Faundez et al., 1995). Our observation is consistent with the report by Hernáez et al.(2017) who performed RNA-Seq transcriptome analysis of changes induced in L929 cells upon infection with VACV. Those results pointed to several alterations in cellular energy metabolism at 4 and 9 hpi, since pathway enrichment analysis with IPA software indicated tricarboxylic acid (TCA) cycle, mitochondrial dysfunction, oxidative phosphorylation or glycolysis as the most significant pathways related to VACV infection (Hernáez et al., 2017).

Within the mitochondrial transport category, 3 genes (Cpt2, Hspd1, Tspo) were significantly down-regulated in both cell types after ECTV infection. Cpt2 encodes carnitine palmitoyltransferase 2 localized on the inner mitochondrial membrane that facilitates transport of long-chain fatty acids into mitochondria for oxidation that is essential for energy production (Qu et al., 2016). Hspd1 is a gene for mitochondria resident chaperone Hsp60 that participates in maintaining mitochondrial biogenesis and energetic metabolism through regulation of folding and assembly of new mitochondria-imported proteins (Deocaris et al., 2006). This mitochondria resident chaperone-encoding gene may also support both pro-apoptotic and pro-survival functions (Wyżewski et al., 2018). Our recent study showed that during later stages of ECTV infection, L929 cells exhibit overexpression of Hsp60 and its cofactor Hsp10, what probably supports maintaining protein homeostasis in mitochondria for promotion of cell survival for efficient virus replication (Wyżewski et al., 2019). Meanwhile, Tspo encodes a mitochondrial translocator protein, primarily located in the outer membrane that regulates mitochondria energy production, calcium signaling, generation of reactive oxygen species (ROS) and mitochondria-induced apoptosis (Gatliff and Campanella, 2012). The other 12 genes within the category of mitochondrial transport were significantly repressed either in L929 fibroblasts (Aip, Bnip3, Timm10b) or RAW 264.7 macrophages (Bak1, Bcl2, Bcl211, Dnajc19, Grpel1, Mipep, Stard3, Trp53, Ucp2) at later stages of ECTV infection. Twelve of the 15 analyzed mitochondrial transport genes are also directly engaged in mitochondrial membrane polarization and potential, targeting proteins to mitochondria, mitochondrion protein import, inner membrane translocation or apoptosis regulation. Moreover, Bcl2, Bcl2l1, Bnip3, Mipep, Grpel1 and Trp53 are reportedly involved in maintaining mitochondrial integrity and functions necessary for ATP production and energy metabolism (Hsiao et al., 2013; GiménezCassina and Danial, 2015; Lanekoff et al., 2016). Only L929 cells up-regulated the Nelf gene for neurofilament light polypeptide, which is responsible for intracellular transport of mitochondria, especially in neuronal cells (Schon and Przedborski, 2011). Taken together, our data suggest that ECTV modulates mitochondrial transport and bioenergetics at later stages of infection in permissive cells.

Next, we analyzed genes of the small molecule transport category that encode the solute carrier family 25 (SLC25) mitochondrial transporters. The SLC25 proteins transport amino acids, carboxylates, nucleotides and cofactors across the inner mitochondrial membrane, thereby functioning as linkers between metabolic processes occurring in the mitochondrial matrix and the cytosol. By transmembrane transporter activity, SLC25 family members regulate essential mitochondria-dependent metabolic processes, including oxidative phosphorylation, fatty acid $\beta$-oxidation, synthesis, methylation and degradation of mitochondrial (mt)DNA, mtRNA and some mitochondrial proteins, induction of necrotic and apoptotic cell death (Haitina et al., 2006; Palmieri, 2013). Therefore, the SLC25 transporters, through facilitating mitochondrial transport of different metabolic intermediates, participate in the production of ATP - the main energy source within cells (Haitina et al., 2006). Our gene expression data show that ECTV infection significantly down-regulates the expression of Slc25a4 and Slc35a13 in both L929 and RAW 264.7 cells. Slc25a4 encodes adenine nucleotide translocase-1 (ANT1), which is a major determinant of cell fate that mediates ADP/ATP exchange across the inner mitochondrial membrane, therefore supplies ATP to the cytosol needed for many cellular processes (Gutiérrez-Aguilar and Baines, 2013). Slc25a13 encodes citrin - a calcium-binding mitochondrial aspartate/glutamate carrier isoform 2 (AGC2), which plays an important role in the aspartate/malate shuttle that is responsible for transport of NADH molecules, produced during glycolysis, from the cytosol to the mitochondrial matrix for oxidative phosphorylation and subsequent ATP production (Amoedo et al., 2016). Taken together, down-regulation of Slc25a4 and Slc25a13 in ECTV-infected cells may result in disturbance of REDOX homeostasis and energy metabolism during later stages of infection. Interestingly, Slc25a23 [encoding short $\mathrm{Ca}^{2+}$-binding mitochondrial carrier (SCaMC) - APC2 (ATP-Mg/phosphate carrier)] and Slc25a31 (encoding ANT4) were up-regulated in infected L929 fibroblasts. SCaMC mediates the ATP-Mg transport in exchange for phosphate, thereby regulates adenine nucleotide-dependent mitochondrial processes, 
including mitochondrial biogenesis, gluconeogenesis and mitochondrial DNA maintenance (Yang et al., 2014). Interestingly, ECTV infection does not alter the ATP level in L929 fibroblasts (Gregorczyk et al., 2018), therefore it is possible that ECTV maintains relatively low mitochondrial activity to allow successful completion of virus replication and release of progeny virions from infected fibroblasts. The low mitochondrial activity does not increase the production of ATP, however, it reduces the formation of free radicals, and therefore cause less molecular damage and slow apoptosis induction (Kaminskyy and Zhivotovsky, 2014). ECTV-infected RAW 264.7 macrophages had a profound down-regulation of other genes in the SLC25 family, including Slc25a3 (phosphate carrier), Slc25a5(ANT2), Slc25a16 (Grave's disease carrier), Slc25a17 (the peroxisomal transporter), Slc25a23 (APC2), Slc25a24 (APC1) and Slc25a37 (iron carrier - mitoferrin-1). This observation indicates a breakdown in mitochondrial transport functions, including oxidative energy metabolism in macrophages during later stages of ECTV infection, possibly leading to initiation of the intrinsic (mitochondrial) pathway of apoptosis. This is consistent with our other study showing increase in the percentage of both early and late apoptotic cells in RAW 264.7 macrophages at late stages of ECTV infection (Gregorczyk et al., 2018).

Reprogramming of cellular energy metabolism is an important feature of viral modulatory strategies, because the host cells provide the energy and molecular precursors indispensable for viral protein synthesis and genome replication (El-Bacha and Da Poian, 2013). VACV, a close relative of ECTV, increased ATP production in HeLa cells infected at $\mathrm{moi}=1$ or $\mathrm{moi}=5$ during later stages of infection. VACV up-regulated mitochondrial genes (ND4 and COII) encoding mitochondrial electron transport chain proteins involved in ATP generation (Chang et al.,2009). On the contrary, genes encoding subunits b, c, e and $f$ of ATP synthase $\mathrm{H}^{+}$transporting mitochondrial $\mathrm{F}_{0}$ complex were decreased in VACV-infected HeLa cells at 6 and 16 hpi (Guerra et al., 2003). Additionally, using a quantitative protein mass spectrometry Chou et al.(2012) revealed that early in VACV infection of HEK293T cells there is suppression of a broad variety of proteins involved in energy metabolism, and such state of suppression is observed until later stages of infection. Since rapid VACV multiplication favors energy generation, and ATP is required in early (Gershowitz et al., 1978; Shuman et al., 1980; Foglesong and Bauer, 1984; Broyles, 1991), intermediate (Boyle et al., 2007) and late (Ericsson et al., 1997) steps of virus production, it is possible that breakdown of energy metabolism observed by Chou et al. (2012) arises from secondary effects multiplexed or overlaid with infection, such as necrosis or mitochondriadependent induction of apoptosis. Meanwhile, increased ATP generation is essential for VACV production, since treatment of HeLa cells with oligomycin, an inhibitor of ATP production, reduced the number of intracellular mature virions (Chang et al., 2009). ATP plays a particularly important role in the assembly of progeny virions of VACV (Greseth and Traktman, 2014) and its distant relative - ASFV (Cobbold et al., 2000). Our other results show that the level of ATP in L929 cells is relatively stable during later stages of ECTV infection (Gregorczyk et al., 2018). It suggests that despite the down-regulation of several genes regulating energy metabolism, fibroblasts are able to maintain cellular ATP level during the infection, likely creating the optimal condition for progeny virus assembly and release.

Our study revealed that in L929 fibroblasts, ECTV did not change the expression of genes within the outer membrane translocation category, whereas in RAW 264.7 macrophages the virus down-regulated Tomm22, Tomm40, Tomm $40 \mathrm{l}$ and Tomm70a that encode subunits of the TOM complex (translocase of the outer mitochondrial membrane). In general, TOM complex mediates import of preproteins into mitochondria, therefore controls mitochondrial biogenesis (Neupert and Herrmann, 2007). It has been found that mitochondria with reduced levels of Tom40 showed impairment in mitochondrial preproteins import and contained reduced amounts of the TOM core complex proteins, Tom22 and Tom6 (Taylor et al., 2003). Therefore, it is plausible that in macrophages under ECTV infection conditions the formation of mature TOM complex and/or import of proteins to mitochondria are altered. Additionally, microarray study of gene expression in VACV-infected HeLa cells revealed that gene encoding cytochrome b5 outer mitochondrial membrane precursor, which is an electron carrier for membrane bound oxygenases, was down-regulated between 2 and 16 hpi (Guerra et al., 2003).

The inner membrane translocation gene category was one of the most down-regulated category in both macrophages (Timm8a1, Timm8b, Timm9, Timm10, Timm17a, Timm17b, Timm22, Timm44, Timm50) and fibroblasts (Timm10b, Timm8b, Timm9, Timm10, Timm22) infected with ECTV. Probably, ECTV affected the stability of TIM (translocase of the inner membrane) complexes and contributed to defects in mitochondrial protein import (Neupert and Herrmann, 2007). Additionally, the inner membrane protein translocases (TIM23 and TIM22) are functionally and structurally interdependent on the complexes of the respiratory chain, also located in the inner mitochondrial membrane. Electrons released by oxidative import can be transferred to the respiratory chain. In addition, there is a physical connection between the pre-sequence translocases and the proton pumping complexes of the respiratory chain (Kulawiak et al., 2013). Therefore, we speculate that impaired mitochondrial im- 
port may negatively regulate the function of the electron transport (respiratory) chain.

Mitochondrial import and synthesis of fatty acids have been shown to play an important role particularly in assembly of VACV virions (Greseth and Traktman, 2014). The blockade of palmitate mitochondrial import and -oxidation by etomoxir and trimetazidine, respectively, resulted in viral yield decrease. Moreover, treatment of BSC40 epithelial cells with pharmacological inhibitors: 5-(Tetradecyloxy)-2-furoic acid (TOFA) and C75, which inhibit the cellular enzymes: acetyl-CoA carboxylase (ACC) and fatty acid synthase (FASN), respectively, significantly inhibited viral yield. Therefore, it is suggested that in VACV-infected cells the tricarboxylic acid (TCA) cycle and aerobic energy production are driven by the conversion of palmitate to acetyl-CoA during $\beta$-oxidation in mitochondria (Greseth and Traktman, 2014).

In the present study, specific analysis of the selected genes with IPA identified "Sirtuin Signaling Pathway" and "Induction of Apoptosis by HIV1" as the top canonical pathways engaged in ECTV infection. "Sirtuin Signaling Pathway" was predicted to be inhibited only in RAW 264.7 macrophages. The mitochondrial sirtuins regulate ATP production, metabolism, cell signaling and apoptosis (Verdin et al., 2010), and have been recently pointed as important factors in defense against viruses (Budayeva et al., 2016). Because sirtuins may influence the susceptibility of a host to viral infections (Budayeva et al., 2016) and their role during a poxviral infection has never been investigated, it is of a great importance to understand their basic functions and antiviral properties in the context of poxviral diseases. Additionally, IPA network enrichment analysis of gene-gene interactions detected major molecular network in L929 ("Protein Trafficking, Respiratory System Development and Function, Auditory and Vestibular System Development and Function") and RAW 264.7 cells ("Protein Trafficking, Cell Morphology, Cellular Function and Maintenance"). Because of the complexity and importance of the protein trafficking for diverse cellular functions, functional annotation also demonstrated connection with degenerative disorders. With cDNA microarrays, Guerra et al. have demonstrated that VACV infection of HeLa cells completely represses genes engaged in metabolic pathways, transcription, translation, subcellular trafficking and apoptosis at 6 and $16 \mathrm{hpi}$. It is assumed that global reduction in mRNA level during VACV infection is due to a general inhibition of host transcription or elevated degradation of cellular mRNAs (Guerra et al., 2003).

ECTV infection differentially regulated apoptotic genes in fibroblasts and macrophages. In L929 cells ECTV down- and up-regulated 2 (Aifm2 and Bnip3) and 1 (Pmaip1) pro-apoptotic gene, respectively, at $24 \mathrm{hpi}$. Yang et al. (2010) observed that at $2 \mathrm{hpi}$ genes related with apoptosis and apoptosis inhibition as well as NF-kB cascade, signal transduction and ligand-mediated signaling were up-regulated in HeLa cells infected with VACV, suggesting more likely a mechanism of host response to viral invasion. Our other experimental data (Gregorczyk et al., 2018) revealed that within the $24 \mathrm{~h}$ replication cycle ECTV infection did not trigger apoptosis in L929 cells even at a higher moi of 5 . In the present study, we used even lower infection dosage $(\mathrm{moi}=1)$ to minimize apoptotic effect caused by massive replication of ECTV. Therefore, changes in mitochondria-related gene expression in fibroblasts, as observed in this study, are attributed only to the infection, and represents the cell-based modulatory strategy of ECTV. A different expression profile was observed in macrophages. ECTV infection led to down-regulation of both pro- and anti-apoptotic genes, what could have resulted in imbalance between pro- and anti-apoptotic mediators of the mitochondrial apoptotic pathway. Occurrence of apoptosis in macrophages infected with ECTV at moi $=5$ is observed as early as $8 \mathrm{hpi}$ (Gregorczyk et al., 2018), therefore it is likely that the dramatic changes in mitochondria-related gene expression observed in these cells may also reflect undergoing apoptotic process triggered as a consequence of severe mitochondria damage under the infection conditions. Meanwhile, VACV has been shown to induce mitochondria-dependent apoptosis in macrophages (Humlova et al., 2002). Moreover, VACV preferentially replicates in human M2 macrophages, and therefore should be considered as a potential treatment agent of M2 macrophage-containing tumors (Byrd et al., 2014). During poxvirus infection, macrophages, on the one hand, play an important role in controlling infection within the skin lesions and respiratory epithelium (Rivera et al., 2007), but on the other hand, they mediate long-range dissemination of the virus (Byrd et al., 2014).

Understanding of basic dichotomy in the functioning of mitochondria during replication of ECTV in permissive cells should contribute to new insights in pathogen-host interactions in the context of model studies on orthopoxvirus pathogenesis and viral infections in general. Additionally, the role of sirtuin signaling pathway during poxvirus infections should be elucidated in future studies, because specific relationship of sirtuins with different metabolic processes makes them a promising target for tailored antiviral therapy.

\section{Conclusions}

ECTV induces cell-specific down-regulation of mitochondria-related genes, responsible for mitochondrial transport, small molecule transport, membrane polariza- 
tion and potential, targeting proteins to mitochondria, inner membrane translocation, and apoptosis. Macrophages exhibit a profound down-regulation of mitochondrial genes, indicating alteration in mitochondria bioenergetics and physiology, possibly leading to the induction of intrinsic pathways of apoptosis. Altered regulation of several mitochondria-related genes without apoptosis induction in fibroblasts may represent a poxviral strategy to control cellular energy metabolism for efficient replication.

Acknowledgment. LSD is a participant in a postdoctoral fellowship program supported by the Leading National Research Center (KNOW), Scientific Consortium "Healthy Animal - Safe Food", No. 05-1/KNOW2/2015 from the Ministry of Science and Higher Education. This work was supported by grant No. UMO-2011/03/B/NZ6/03856 (to M.N.) from the National Science Center in Cracow, Poland.

Supplementary information is available in the online version of the paper.

\section{References}

Abrahao J, Oliveira TML, Campos RK, Madureira MC, Kroon EG, Lobato ZIP (2009): Bovine vaccinia outbreaks: detection and isolation of vaccinia virus in milk samples. Foodborne Pathog. Dis. 6, 1141-1146. https://doi. org/10.1089/fpd.2009.0324

Amoedo ND, Punzi G, Obre E, Lacombe D, De Grassi A, Pierri CL, Rossignol R (2016): AGC1/2, the mitochondrial aspartate-glutamate carriers. Biochim. Biophys. Acta 1863, 2394-2412.https://doi.org/10.1016/j.bbamcr.2016.04.011

Anand SK, Suresh KT (2013): Viruses as modulators of mitochondrial functions. Adv. Virol. 2013, 738794. https:// doi.org/10.1155/2013/738794

Bertram R, Gram Pedersen M, Luciani DS, Sherman A (2006): A simplified model for mitochondrial ATP production. J. Theor. Biol. 243, 575-586. https://doi.org/10.1016/j. jtbi.2006.07.019

Bidgood SR, Mercer J (2015): Cloak and dagger: alternative immune evasion and modulation strategies of poxviruses. Viruses 7, 4800-4825. https://doi.org/10.3390/ v7082844

Boyle KA, Arps L, Traktman P (2007): Biochemical and genetic analysis of the vaccinia virus $\mathrm{d} 5$ protein: Multimerization-dependent ATPase activity is required to support viral DNA replication. J. Virol. 81, 844-859. https://doi. org/10.1128/JVI.02217-06

Broyles SS (1991): A role for ATP hydrolysis in vaccinia virus early gene transcription. J. Biol. Chem. 266, 15545-15548.

Brum LM, Lopez MC, Varela JC, Baker HV, Moyer RW (2003): Microarray analysis of A549 cells infected with rabbitpox virus (RPV): a comparison of wild-type RPV and RPV deleted for the host range gene, SPI-1. Virology 315,322334. https://doi.org/10.1016/S0042-6822(03)00532-4
Budayeva HG, Rowland EA, Cristea IM (2016): Intricate roles of mammalian sirtuins in defense against viral pathogens. J. Virol. 90, 5-8. https://doi.org/10.1128/ JVI.03220-14

Buller RM (2004): Mousepox: a small animal model for biodefense research. Appl. Biosaf. 9, 10-19. https://doi. org/10.1177/153567600400900103

Byrd D, Shepherd N, Lan J, Hu N, Amet T, Yang K, et al. (2014): Primary human macrophages serve as vehicles for vaccinia virus replication and dissemination. J. Virol. 88, 6819-6831. https://doi.org/10.1128/JVI.03726-13

Castanier C, Garcin D, Vazquez A, Arnoult D (2009): Mitochondrial dynamics regulate the RIG-I-like receptor antiviral pathway. EMBO Rep. 11, 133-138. https://doi. org/10.1038/embor.2009.258

Chang CW, Li HC, Hsu CF, Chang CY, Lo SY (2009): Increased ATP generation in the host cell is required for efficient vaccinia virus production. J. Biomed. Sci. 16, 80. https:// doi.org/10.1186/1423-0127-16-80

Chou W, Ngo T, Gershon PD (2012): An overview of the vaccinia virus infectome: a survey of the proteins of the poxvirus-infected cell. J. Virol. 86, 1487-1499. https:// doi.org/10.1128/JVI.06084-11

Cobbold C, Brookes SM, Wileman T (2000): Biochemical requirements of virus wrapping by the endoplasmic reticulum: involvement of ATP and endoplasmic reticulum calcium store during envelopment of African swine fever virus. J. Virol. 74, 2151-2160. https://doi. org/10.1128/JVI.74.5.2151-2160.2000

Deocaris CC, Kaul SC, Wadhwa R (2006): On the brotherhood of the mitochondrial chaperones mortalin and heat shock protein 60. Cell Stress Chap. 11, 116-128. https:// doi.org/10.1379/CSC-144R.1

El-Bacha T, Da Poian AT (2013): Virus-induced changes in mitochondrial bioenergetics as potential targets for therapy. Biology 45, 41-46. https://doi.org/10.1016/j. biocel.2012.09.021

Ericsson M, Sodeik B, Locker JK, Griffiths G (1997): In vitro reconstitution of an intermediate assembly stage of vaccinia virus. Virology 235, 218-227. https://doi. org/10.1006/viro.1997.8683

Foglesong PD, Bauer WR (1984): Effects of ATP and inhibitory factors on the activity of vaccinia virus type I topoisomerase. J. Virol. 49, 1-8. https://doi.org/10.1128/ JVI.49.1.1-8.1984

Gatliff J, Campanella M (2012): The $18 \mathrm{kDa}$ translocator protein (TSPO): a new perspective in mitochondrial biology. Curr. Mol. Med. 12, 356-368. https://doi. org/10.2174/1566524011207040356

Gershowitz A, Boone RF, Moss B (1978): Multiple roles for ATP in the synthesis and processing of mRNA by vaccinia virus: specific inhibitory effects of adenosine (beta,gamma-imido) triphosphate. J.Virol.27,399-408. https://doi.org/10.1128/JVI.27.2.399-408.1978

Giménez-Cassina A, Danial NN (2015): Regulation of mitochondrial nutrient and energy metabolism by BCL-2 family proteins. Trends Endocrinol. Metab. 26,165-175. https://doi.org/10.1016/j.tem.2015.02.004 
Gregorczyk KP, Szulc-Dąbrowska L, Wyżewski Z, Struzik J, Niemiałtowski $\mathrm{M}$ (2014): Changes in the mitochondrial network during ectromelia virus infection of permissive L929 cells. Acta Biochim. Pol. 61, 171-177. https:// doi.org/10.18388/abp.2014_1940

Gregorczyk KP, Wyżewski Z, Szczepanowska J, Toka FN, Mielcarska MB, Bossowska-Nowicka M et al.(2018): Ectromelia virus affects mitochondrial network morphology, distribution, and physiology in murine fibroblasts and macrophage cell line. Viruses 10, pii:E266. https://doi. org/10.3390/v10050266

Greseth MD, Traktman P (2014): De novo fatty acid biosynthesis contributes significantly to establishment of a bioenergetically favorable environment for vaccinia virus infection. PLoS Pathog.10, e1004021. https://doi. org/10.1371/journal.ppat.1004021

Guerra S, López-Fernández LA, Pascual-Montano A, Muñoz M, Harshman K, Esteban M (2003): Cellular gene expression survey of vaccinia virus infection of human HeLa cells. J. Virol. 77, 6493-6506. https://doi.org/10.1128/ JVI.77.11.6493-6506.2003

Gutiérrez-Aguilar M, Baines CP (2013): Physiological and pathological roles of mitochondrial SLC25 carriers. Biochem. J. 454, 371-386. https://doi.org/10.1042/BJ20121753

Haitina T, Lindblom J, Renström T, Fredriksson R (2006): Fourteen novel human members of mitochondrial solute carrier family 25 (SLC25) widely expressed in the central nervous system. Genomics 88,779-790. https://doi. org/10.1016/i.ygeno.2006.06.016

Hernáez B, Alonso G, Alonso-Lobo JM, Rastrojo A, Fischer C, Sauer S, et al. (2017): RNA-Seq Based Transcriptome analysis of the type I interferon host response upon vaccinia virus infection of mouse cells. J. Immunol. Res. 2017,5157626. https://doi.org/10.1155/2017/5157626

Hsiao CP, Wang D, Kaushal A, Saligan L (2013): Mitochondriarelated gene expression changes are associated with fatigue in patients with nonmetastatic prostate cancer receiving external beam radiation therapy. Cancer Nurs. 36, 189-197. https://doi.org/10.1097/ NCC.0b013e318263f514

Hu M, Li HM, Bogoyevitch MA, Jans DA (2017): Mitochondrial protein $\mathrm{p} 32 / \mathrm{HAPB} 1 / \mathrm{gClqR} / \mathrm{Clqbp}$ is required for efficient respiratory syncytial virus production. Biochem. Biophys. Res. Commun. 489, 460-465. https://doi. org/10.1016/j.bbrc.2017.05.171

Humlova Z, Vokurka M, Esteban M, Melkova Z (2002): Vaccinia virus induces apoptosis of infected macrophages. J. Gen.Virol. 83,2821-2832. https://doi.org/10.1099/00221317-83-11-2821

Kaminskyy VO, Zhivotovsky B (2014): Free radicals in cross talk between autophagy and apoptosis. Antioxid. Redox Signal.21, 86-102.https://doi.org/10.1089/ars.2013.5746

Khan M, Syed GS, Kim JS, Siddiqui JA (2015): Mitochondrial dynamics and viral infections: A close nexus. Biochim. Biophys. Acta 1853, 2822-2833. https://doi.org/10.1016/j. bbamcr.2014.12.040
Koshiba T (2013): Mitochondrial-mediated antiviral immunity. Biochim. Biophys. Acta 1833, 225-232. https://doi. org/10.1016/j.bbamcr.2012.03.005

Kulawiak B, Höpker J, Gebertc M, Guiard B, Wiedemann N, Gebert N (2013): The mitochondrial protein import machinery has multiple connections to the respiratory chain. Biochim. Biophys. Acta 1827, 612-626. https://doi. org/10.1016/j.bbabio.2012.12.004

Lanekoff I, Cha J, Kyle JE, Dey SK, Laskin J, Burnum-Johnson KE (2016): Trp53 deficient mice predisposed to preterm birth display region-specific lipid alterations at the embryo implantation site. Sci. Rep. 6, 33023. https:// doi.org/10.1038/srep33023

McInerney J, Papasouliotis K, Simpson K, English K, Cook S, Milne E et al. (2016): Pulmonary cowpox in cats: five cases. J. Feline Med. Surg. 18, 518-525. https://doi. org/10.1177/1098612X15583344

Murray L, Edwards L, Tuppurainen ESM, Bachanek-Bankowska K, Oura CAL, Mioulet V et al. (2013): Detection of capripoxvirus DNA using a novel loop-mediated isothermal amplification assay. BMC Vet Res 9, 90. https://doi. org/10.1186/1746-6148-9-90

Neupert W, Herrmann JM (2007): Translocation of proteins into mitochondria.Annu. Rev. Biochem.76,723-749. https:// doi.org/10.1146/annurev.biochem.76.052705.163409

Palmieri F (2013): The mitochondrial transporter family SLC25: Identification, properties and physiopathology. Mol. Aspects Med. 34, 465-484. https://doi.org/10.1016/j. mam.2012.05.005

Parker S, Siddiqui AM, Painter G, Schriewer J, Buller RM (2010): Ectromelia virus infections of mice as a model to support the licensure of anti-orthopoxvirus therapeutics. Viruses 2,1918-1932. https://doi.org/10.3390/v2091918

Qu Q, Zeng F, Liu X, Wang QJ, Deng F (2016): Fatty acid oxidation and carnitine palmitoyltransferase I: emerging therapeutic targets in cancer. Cell Death. Dis. 7, e2226. https://doi.org/10.1038/cddis.2016.132

Radovanović J, Boricić I, Todorović I, Janković-Hladni M, Korać A (1999): Comparative ultrastructural studies on mitochondrial pathology in the liver of AIDS patients: clusters of mitochondria, protuberances, „minimitochondria,“ vacuoles, and virus-like particles. Ultrastruct. Pathol. 23, 19-24. https://doi. org/10.1080/019131299281798

Reed KD, Melski JW, Graham MB, Regnery RL, Sotir MJ, Wegner MV et al. (2004): The detection of monkeypox in humans in the Western Hemisphere. N. Engl. J. Med. 350, 342-350. https://doi.org/10.1056/NEJMoa032299

Rivera R, Hutchens M, Luker KE, Sonstein J, Curtis JL, Luker GD (2007): Murine alveolar macrophages limit replication of vaccinia virus. Virology 363, 48-58. https://doi. org/10.1016/j.virol.2007.01.033

Rohde J, Emschermann F, Knittler MR, Rziha HJ (2012): Orf virus interferes with MHC class I surface expression by targeting vesicular transport and Golgi. BMC Vet. Res. 8, 114. https://doi.org/10.1186/1746-6148-8-114 
Rojo G, Chamorro M, Salas KL, Viñuela E, Cuezva JM, Salas J (1998): Migration of mitochondria to viral assembly sites in African swine fever virus-infected cells. J. Virol.72,7583-7588. https://doi.org/10.1128/JVI.72.9.7583$\underline{7588.1998}$

Schon EA, Przedborski S (2011): Mitochondria: The next (neurode) generation. Neuron 70, 1033-1053. https://doi. org/10.1016/j.neuron.2011.06.003

Shchelkunov SN (2013): An increasing danger of zoonotic orthopoxvirus infections. PLoS Pathog. 9, e1003756. https:// doi.org/10.1371/journal.ppat.1003756

Shuman S, Spencer E, Furneaux H, Hurwitz J (1980): The role of ATP in in vitro vaccinia virus RNA synthesis effects of AMP-PNP and ATP gamma S. J. Biol. Chem. 255, 5396-5403.

Spohr de Faundez I, Gieryńska M, Niemiałtowski MG, Malicka E, Popis A (1995): Ectromelia virus establishes a persistent infection in spleen dendritic cells and macrophages of BALB/c mice following the acute disease. Adv. Exp. Med. Biol. 378, 257-261. https://doi. org/10.1007/978-1-4615-1971-3_57

Szulc-Dabrowska L, Gregorczyk KP, Struzik J, BoratynskaJasinska A, Szczepanowska J, Wyzewski Z et al.(2016): Remodeling of the fibroblast cytoskeletal architecture during the replication cycle of Ectromelia virus: A morphological in vitro study in a murine cell line. Cytoskeleton 7,396-417. https://doi.org/10.1002/cm.21308

Szulc-Dąbrowska L, Struzik J, Cymerys J, Winnicka A, Nowak $Z$, Toka FN et al. (2017a): The in vitro inhibitory effect of ectromelia virus infection on innate and adaptive immune properties of GM-CSF-derived bone marrow cells is mouse strain-independent. Front. Microbiol. 8, 2539. https://doi.org/10.3389/fmicb.2017.02539

Szulc-Dąbrowska L, Struzik J, Ostrowska A, Guzera M, Toka FN, Bossowska-Nowicka M et al. (2017b): Functional paralysis of GM-CSF-derived bone marrow cells productively infected with ectromelia virus. PLOS ONE 12, 0179166. https://doi.org/10.1371/journal.pone.0179166
Tack DM, Reynolds MG (2011): Zoonotic poxviruses associated with companion animals. Animals 1,377-395. https:// doi.org/10.3390/ani1040377

Taylor RD, McHale BJ, Nargang FE (2003): Characterization of Neurospora crassa Tom40-deficient mutants and effect of specific mutations on Tom40 assembly. J. Biol. Chem. 278, 765-775. https://doi.org/10.1074/jbc. M208083200

Verdin E, Hirschey MD, Finley LWS, Haigis MC (2010): Sirtuin regulation of mitochondria - energy production, apoptosis, and signaling. Trends Biochem. Sci. 35, 669-675. https://doi.org/10.1016/j.tibs.2010.07.003

Wyżewski Z, Gregorczyk KP, Struzik J, Niemiałtowski M, Szulc-Dąbrowska L (2016): MAVS protein and its interactions with hepatitis A, B and C viruses. Postepy Hig. Med. Dosw. 70, 14-24. https://doi.org/10.5604/ $\underline{17322693.1192925}$

Wyżewski Z, Gregorczyk KP, Szczepanowska J, Szulc-Dąbrowska $\mathrm{L}$ (2018): Functional role of Hsp60 as a positive regulator of human viral infection progression. Acta Virol.62, 33-40. https://doi.org/10.4149/av_2018_104

Wyżewski Z, Gregorczyk-Zboroch KP, Mielcarska MB, Bossowska-Nowicka M, Struzik J, Szczepanowska J, Toka FN, Niemiałtowski MG, Szulc-Dąbrowska L (2019): Mitochondrial heat shock response induced by ectromelia virus is accompanied by reduced apoptotic potential in murine L929 fibroblasts. Arch. Immunol. Ther. Exp. (Warsz.) 67, 401-414. https://doi.org/10.1007/s00005019-00554-5

Yang Q, Brüschweiler S, Chou JJ (2014): A self-sequestered calmodulin-like Ca2 + sensor of mitochondrial SCaMC carrier and its implication to Ca2+-dependent ATP$\mathrm{Mg} / \mathrm{Pi}$ transport. Structure 22, 209-217. https://doi. org/10.1016/j.str.2013.10.018

Yang Z, Bruno DP, Martens CA, Porcella SF, Moss B (2010): Simultaneous high-resolution analysis of vaccinia virus and host cell transcriptomes by deep RNA sequencing. Proc. Natl. Acad. USA 107, 11513-11518. https://doi. org/10.1073/pnas.1006594107 


\title{
SUPPLEMENTARY INFORMATION
}

\section{Mitochondria-related gene expression profiles in murine fibroblasts and macrophages during later stages of ectromelia virus infection in vitro}

\author{
L. SZULC-DĄBROWSKA ${ }^{1,2}$, Z. WYŻEWSKI ${ }^{1,3}$, K. P. GREGORCZYK-ZBOROCH ${ }^{1}$, F.N. TOKA ${ }^{1,2}$, J. SZCZEPANOWSKA ${ }^{4}$, \\ J. STRUZIK ${ }^{1}$, Z. NOWAK-ŻYCZYŃSKA ${ }^{5}$, M. GIERYŃSKA', M. NIEMIAŁTOWSKI ${ }^{1 \#}$
}

${ }^{1}$ Department of Preclinical Sciences, Institute of Veterinary Medicine, Warsaw University of Life Sciences-SGGW, Ciszewskiego

8, 02-786 Warsaw, Poland; ${ }^{2}$ Integrative Mammalian Research Center, Ross University School of Veterinary Medicine, P.O. Box

334, Basseterre, St. Kitts, West Indies; ${ }^{3}$ Faculty of Biological Sciences, Cardinal Stefan Wyszynski University in Warsaw, Warsaw, Poland; ${ }^{4}$ Nencki Institute of Experimental Biology Polish Academy of Sciences, Warsaw, Poland; ${ }^{5}$ Department of Animal

Genetics and Conservation, Institute of Animal Sciences, Warsaw University of Life Sciences-SGGW, Warsaw, Poland

Received July 7, 2019; accepted December 16, 2019

Table S1. Gene list description of Mouse Mitochondria RT $^{2}$ Profiler PCR Array (Qiagen)

\begin{tabular}{|c|c|c|c|c|}
\hline Position & UniGene & GenBank & Symbol & Description \\
\hline A01 & Mm.286309 & NM_178058 & Aifm2 & Apoptosis-inducing factor, mitochondrion-associated 2 \\
\hline $\mathrm{A} 02$ & Mm.10433 & NM_016666 & Aip & Aryl-hydrocarbon receptor-interacting protein \\
\hline $\mathrm{A} 03$ & Mm.2443 & NM_007523 & Bak1 & BCL2-antagonist/killer 1 \\
\hline A04 & Mm.7660 & NM_133234 & $\mathrm{Bbc} 3$ & BCL2 binding component 3 \\
\hline A05 & Mm.257460 & NM_009741 & $\mathrm{Bcl} 2$ & B-cell leukemia/lymphoma 2 \\
\hline A06 & Mm.238213 & NM_009743 & Bcl2l1 & Bcl2-like 1 \\
\hline A07 & Mm.235081 & NM_007544 & Bid & BH3 interacting domain death agonist \\
\hline A08 & Mm.378890 & NM_009760 & Bnip3 & BCL2/adenovirus E1B interacting protein 3 \\
\hline A09 & $\mathrm{Mm} .4733$ & NM_009877 & Cdkn2a & Cyclin-dependent kinase inhibitor $2 \mathrm{~A}$ \\
\hline A10 & Mm.340211 & NM_178379 & Cox10 & $\begin{array}{l}\text { COX10 homolog, cytochrome c oxidase assembly protein, heme A: farnesyl- } \\
\text { transferase (yeast) }\end{array}$ \\
\hline A11 & Mm.319697 & NM_001033310 & Cox18 & COX18 cytochrome c oxidase assembly homolog (S. cerevisiae) \\
\hline A12 & Mm.227738 & NM_009948 & Cptlb & Carnitine palmitoyltransferase $1 \mathrm{~b}$, muscle \\
\hline B01 & Mm.307620 & NM_009949 & Cpt2 & Carnitine palmitoyltransferase 2 \\
\hline B02 & Mm.274266 & NM_026332 & Dnajc19 & DnaJ (Hsp40) homolog, subfamily C, member 19 \\
\hline B03 & Mm.218820 & NM_152816 & Dnmll & Dynamin 1-like \\
\hline B04 & Mm.25849 & NM_025562 & Fis1 & Fission 1 (mitochondrial outer membrane) homolog (yeast) \\
\hline B05 & Mm.220330 & NM_019502 & Fxc1 & Fractured callus expressed transcript 1 \\
\hline B06 & Mm.21535 & NM_024478 & Grpel1 & GrpE-like 1, mitochondria \\
\hline B07 & Mm.1843 & NM_010480 & Hsp90aal & Heat shock protein 90, alpha (cytosolic), class A member 1 \\
\hline B08 & Mm.1777 & NM_010477 & Hspd1 & Heat shock protein 1 (chaperonin) \\
\hline B09 & Mm.272253 & NM_028260 & Immpll & IMP1 inner mitochondrial membrane peptidase-like (S. cerevisiae) \\
\hline $\mathrm{B} 10$ & Mm.363813 & NM_053122 & Immp2l & IMP2 inner mitochondrial membrane peptidase-like (S. cerevisiae) \\
\hline $\mathrm{B} 11$ & Mm.217027 & NM_028233 & Lrpprc & Leucine-rich PPR-motif containing \\
\hline B12 & Mm.290414 & NM_024200 & Mfnl & Mitofusin 1 \\
\hline $\mathrm{CO1}$ & Mm.154312 & NM_133201 & Mfn2 & Mitofusin 2 \\
\hline $\mathrm{CO} 2$ & Mm.274650 & NM_027436 & Mipep & Mitochondrial intermediate peptidase \\
\hline $\mathrm{CO3}$ & Mm.126870 & NM_144898 & Mstol & Misato homolog 1 (Drosophila) \\
\hline $\mathrm{C04}$ & Mm.292613 & NM_016804 & Mtx2 & Metaxin 2 \\
\hline $\mathrm{CO5}$ & Mm.1956 & NM_010910 & Nefl & Neurofilament, light polypeptide \\
\hline $\mathrm{CO6}$ & Mm.274285 & NM_133752 & Opal & Optic atrophy 1 homolog (human) \\
\hline
\end{tabular}

E-mail: lidia_szulc@sggw.edu.pl; phone: +48-22 59360 66. "In memoriam. 
Table S1. Gene list description of Mouse Mitochondria RT2 Profiler PCR Array (Qiagen) - continued

\begin{tabular}{|c|c|c|c|c|}
\hline Position & UniGene & GenBank & Symbol & Description \\
\hline $\mathrm{CO7}$ & Mm.271878 & NM_021451 & Pmaip1 & Phorbol-12-myristate-13-acetate-induced protein 1 \\
\hline C08 & Mm.477760 & NM_021536 & Rhot1 & Ras homolog gene family, member T1 \\
\hline C09 & Mm.277233 & NM_145999 & Rhot2 & Ras homolog gene family, member T2 \\
\hline $\mathrm{C} 10$ & Mm.44482 & NM_018754 & Sfn & Stratifin \\
\hline $\mathrm{C} 11$ & Mm.271775 & NM_019464 & Sh3glb1 & SH3-domain GRB2-like B1 (endophilin) \\
\hline $\mathrm{C} 12$ & Mm.229291 & NM_153150 & Slc25al & Solute carrier family 25 (mitochondrial carrier, citrate transporter), member 1 \\
\hline D01 & Mm.3991 & NM_013770 & Slc25a10 & $\begin{array}{l}\text { Solute carrier family } 25 \text { (mitochondrial carrier, dicarboxylate transporter), } \\
\text { member } 10\end{array}$ \\
\hline D02 & Mm.30928 & NM_172436 & Slc25a12 & Solute carrier family 25 (mitochondrial carrier, Aralar), member 12 \\
\hline D03 & Mm.24513 & NM_015829 & Slc25a13 & $\begin{array}{l}\text { Solute carrier family } 25 \text { (mitochondrial carrier, adenine nucleotide } \\
\text { translocator), member } 13\end{array}$ \\
\hline D04 & Mm.34953 & NM_011398 & Slc25a14 & Solute carrier family 25 (mitochondrial carrier, brain), member 14 \\
\hline D05 & Mm.200907 & NM_181325 & Slc25a15 & $\begin{array}{l}\text { Solute carrier family } 25 \text { (mitochondrial carrier ornithine transporter), } \\
\text { member } 15\end{array}$ \\
\hline D06 & Mm.37457 & NM_175194 & Slc25a16 & $\begin{array}{l}\text { Solute carrier family } 25 \text { (mitochondrial carrier, Graves disease autoantigen), } \\
\text { member } 16\end{array}$ \\
\hline D07 & Mm.222536 & NM_011399 & Slc25a17 & $\begin{array}{l}\text { Solute carrier family } 25 \text { (mitochondrial carrier, peroxisomal membrane } \\
\text { protein), member } 17\end{array}$ \\
\hline D08 & Mm.383426 & NM_026071 & Slc25a19 & $\begin{array}{l}\text { Solute carrier family } 25 \text { (mitochondrial thiamine pyrophosphate carrier), } \\
\text { member } 19\end{array}$ \\
\hline D09 & Mm.193029 & NM_001159275 & Slc25a2 & $\begin{array}{l}\text { Solute carrier family } 25 \text { (mitochondrial carrier, ornithine transporter) } \\
\text { member } 2\end{array}$ \\
\hline D10 & Mm.29666 & NM_020520 & Slc25a20 & $\begin{array}{l}\text { Solute carrier family } 25 \text { (mitochondrial carnitine/acylcarnitine translocase), } \\
\text { member } 20\end{array}$ \\
\hline D11 & Mm.32835 & NM_172577 & Slc25a21 & $\begin{array}{l}\text { Solute carrier family } 25 \text { (mitochondrial oxodicarboxylate carrier), member } \\
21\end{array}$ \\
\hline D12 & Mm.33729 & NM_026646 & Slc25a22 & Solute carrier family 25 (mitochondrial carrier, glutamate), member 22 \\
\hline E01 & Mm.23720 & NM_025877 & Slc25a23 & $\begin{array}{l}\text { Solute carrier family } 25 \text { (mitochondrial carrier; phosphate carrier), } \\
\text { member } 23\end{array}$ \\
\hline E02 & Mm.33574 & NM_172685 & Slc25a24 & $\begin{array}{l}\text { Solute carrier family } 25 \text { (mitochondrial carrier; phosphate carrier), } \\
\text { member } 24\end{array}$ \\
\hline E03 & Mm.37395 & NM_146118 & Slc25a25 & $\begin{array}{l}\text { Solute carrier family } 25 \text { (mitochondrial carrier; phosphate carrier), } \\
\text { member } 25\end{array}$ \\
\hline E04 & Mm.288697 & NM_028711 & Slc25a27 & Solute carrier family 25 , member 27 \\
\hline E05 & $\mathrm{Mm} .298$ & NM_133668 & Slc25a3 & $\begin{array}{l}\text { Solute carrier family } 25 \text { (mitochondrial carrier; phosphate carrier), } \\
\text { member } 3\end{array}$ \\
\hline E06 & Mm.46067 & NM_026232 & Slc25a30 & Solute carrier family 25 , member 30 \\
\hline E07 & Mm.78691 & NM_178386 & Slc25a31 & $\begin{array}{l}\text { Solute carrier family } 25 \text { (mitochondrial carrier; adenine nucleotide } \\
\text { translocator), member } 31\end{array}$ \\
\hline E08 & Mm.293635 & NM_026331 & Slc25a37 & Solute carrier family 25 , member 37 \\
\hline E09 & Mm.16228 & NM_007450 & Slc25a4 & $\begin{array}{l}\text { Solute carrier family } 25 \text { (mitochondrial carrier, adenine nucleotide } \\
\text { translocator), member } 4\end{array}$ \\
\hline E10 & Mm.371544 & NM_007451 & Slc25a5 & $\begin{array}{l}\text { Solute carrier family } 25 \text { (mitochondrial carrier, adenine nucleotide } \\
\text { translocator), member } 5\end{array}$ \\
\hline E11 & Mm.276325 & NM_011434 & Sod1 & Superoxide dismutase 1 , soluble \\
\hline E12 & Mm.290876 & NM_013671 & Sod2 & Superoxide dismutase 2 , mitochondrial \\
\hline F01 & Mm.265546 & NM_021547 & Stard3 & START domain containing 3 \\
\hline F02 & Mm.268483 & NM_181516 & Taz & Tafazzin \\
\hline F03 & Mm.21826 & NM_013899 & Timm10 & Translocase of inner mitochondrial membrane 10 homolog (yeast) \\
\hline F04 & Mm.2368 & NM_011590 & Timm17a & Translocase of inner mitochondrial membrane $17 a$ \\
\hline F05 & Mm.27393 & NM_011591 & Timm17b & Translocase of inner mitochondrial membrane 17b \\
\hline F06 & Mm.18803 & NM_019818 & Timm22 & Translocase of inner mitochondrial membrane 22 homolog (yeast) \\
\hline F07 & Mm.303703 & NM_016897 & Timm23 & Translocase of inner mitochondrial membrane 23 homolog (yeast) \\
\hline F08 & Mm.195249 & NM_011592 & Timm44 & Translocase of inner mitochondrial membrane 44 \\
\hline F09 & Mm.167913 & NM_025616 & Timm50 & Translocase of inner mitochondrial membrane 50 homolog (yeast) \\
\hline F10 & Mm.214504 & NM_013898 & Timm8al & Translocase of inner mitochondrial membrane 8 homolog al (yeast) \\
\hline F11 & Mm.379061 & NM_013897 & Timm $8 \mathrm{~b}$ & Translocase of inner mitochondrial membrane 8 homolog b (yeast) \\
\hline F12 & Mm.207767 & NM_001024853 & Timm9 & Translocase of inner mitochondrial membrane 9 homolog (yeast) \\
\hline G01 & Mm.6932 & NM_024214 & Tomm20 & Translocase of outer mitochondrial membrane 20 homolog (yeast) \\
\hline G02 & Mm.246435 & NM_172609 & Tomm22 & Translocase of outer mitochondrial membrane 22 homolog (yeast) \\
\hline G03 & $\mathrm{Mm} .23173$ & NM_025996 & Tomm34 & Translocase of outer mitochondrial membrane 34 \\
\hline G04 & Mm.416870 & NM_016871 & Tomm40 & Translocase of outer mitochondrial membrane 40 homolog (yeast) \\
\hline G05 & Mm.288374 & NM_001037170 & Tomm401 & Translocase of outer mitochondrial membrane 40 homolog-like (yeast) \\
\hline G06 & Mm.213292 & NM_138599 & Tomm70a & Translocase of outer mitochondrial membrane 70 homolog A (yeast) \\
\hline G07 & Mm.222 & NM_011640 & $\operatorname{Trp} 53$ & Transformation related protein 53 \\
\hline G08 & Mm.1508 & NM_009775 & Tspo & Translocator protein \\
\hline
\end{tabular}


Table S1. Gene list description of Mouse Mitochondria RT ${ }^{2}$ Profiler PCR Array (Qiagen) - continued

\begin{tabular}{lllll}
\hline Position & UniGene & GenBank & Symbol & Description \\
\hline G09 & Mm.4177 & NM_009463 & Ucp1 & Uncoupling protein 1 (mitochondrial, proton carrier) \\
G10 & Mm.171378 & NM_011671 & Ucp2 & Uncoupling protein 2 (mitochondrial, proton carrier) \\
G11 & Mm.6254 & NM_009464 & Ucp3 & Uncoupling protein 3 (mitochondrial, proton carrier) \\
G12 & Mm.34779 & NM_013840 & Uxt & Ubiquitously expressed transcript \\
H01 & Mm.328431 & NM_007393 & Actb & Actin, beta \\
H02 & Mm.163 & NM_009735 & B2m & Beta-2 microglobulin \\
H03 & Mm.343110 & NM_008084 & Gapdh & Glyceraldehyde-3-phosphate dehydrogenase \\
H04 & Mm.3317 & NM_010368 & Gusb & Glucuronidase, beta \\
H05 & Mm.2180 & NM_008302 & Hsp90ab1 & Heat shock protein 90 alpha (cytosolic), class B member 1 \\
H06 & N/A & SA_00106 & MGDC & Mouse Genomic DNA Contamination \\
H07 & N/A & SA_00104 & RTC & Reverse Transcription Control \\
H08 & N/A & SA_00104 & RTC & Reverse Transcription Control \\
H09 & N/A & SA_00104 & RTC & Reverse Transcription Control \\
H10 & N/A & SA_00103 & PPC & Positive PCR Control \\
H11 & N/A & SA_00103 & PPC & Positive PCR Control \\
H12 & N/A & SA_00103 & PPC & Positive PCR Control \\
\hline
\end{tabular}

